\title{
A global climatology of stratosphere-troposphere exchange using the ERA-Interim data set from 1979 to 2011
}

\author{
B. Škerlak, M. Sprenger, and H. Wernli \\ ETH Zurich, IAC, Universitätstrasse 16, 8092 Zürich, Switzerland \\ Correspondence to: B. Škerlak (bojan.skerlak@env.ethz.ch)
}

Received: 15 March 2013 - Published in Atmos. Chem. Phys. Discuss.: 2 May 2013

Revised: 21 September 2013 - Accepted: 11 December 2013 - Published: 27 January 2014

\begin{abstract}
In this study we use the ERA-Interim reanalysis data set from the European Centre for Medium-Range Weather Forecasts (ECMWF) and a refined version of a previously developed Lagrangian methodology to compile a global $33 \mathrm{yr}$ climatology of stratosphere-troposphere exchange (STE) from 1979 to 2011. Fluxes of mass and ozone are calculated across the tropopause, pressure surfaces in the troposphere, and the top of the planetary boundary layer (PBL). This climatology provides a state-of-the-art quantification of the geographical distribution of STE and the preferred transport pathways, as well as insight into the temporal evolution of STE during the last $33 \mathrm{yr}$.

We confirm the distinct zonal and seasonal asymmetry found in previous studies using comparable methods. The subset of "deep STE", where stratospheric air reaches the PBL within 4 days or vice versa, shows especially strong geographical and seasonal variations. The global hotspots for deep STE are found along the west coast of North America and over the Tibetan Plateau, especially in boreal winter and spring. An analysis of the time series reveals significant positive trends of the net downward mass flux and of deep STE in both directions, which are particularly large over North America.

The downward ozone flux across the tropopause is dominated by the seasonal cycle of ozone concentrations at the tropopause and peaks in summer, when the mass flux is nearly at its minimum. For the subset of deep STE events, the situation is reversed and the downward ozone flux into the PBL is dominated by the mass flux and peaks in early spring. Thus surface ozone concentration along the west coast of North America and around the Tibetan Plateau are likely to be influenced by deep stratospheric intrusions.
\end{abstract}

We discuss the sensitivity of our results on the choice of the control surface representing the tropopause, the horizontal and vertical resolution of the trajectory starting grid, and the minimum residence time $\tau$ used to filter out transient STE trajectories.

\section{Introduction}

Stratosphere-troposphere exchange (STE) has important impacts on atmospheric chemistry: it changes the oxidative capacity of the troposphere (e.g. Kentarchos and Roelofs, 2003) and potentially also affects the climate system because ozone and water vapour are potent greenhouse gases (e.g. Gauss et al., 2003; Forster et al., 2007).

Although it has been known for roughly $50 \mathrm{yr}$ that stratospheric ozone can be brought into the troposphere during STE events (Junge, 1962; Danielsen, 1968) and add to local photochemical production, the relative importance of these sources is not yet entirely certain. Modelling studies (e.g. Roelofs and Lelieveld, 1997) indicate that the stratospheric contribution to ozone in the troposphere could be as large as that from net photochemical production, which was also confirmed in a more recent multi-model ensemble simulation (Stevenson et al., 2006). This contribution, albeit only known with rather large uncertainty (Wild, 2007), is likely to increase over the next decades (Zeng and Pyle, 2003; Collins et al., 2003; Hegglin and Shepherd, 2009), which further emphasizes the importance of STE for tropospheric chemistry.

While ozone in the upper troposphere is mainly relevant as a greenhouse gas and oxidizer, deep STE down to the surface can also contribute to enhanced ozone levels at the ground and affect plant and human physiology 
(e.g. Lippmann, 1989; Knowlton et al., 2004). It is therefore not only important to quantify the global net ozone flux across the tropopause but also to investigate the transport and mixing after the crossing (e.g. Bourqui and Trepanier, 2010). The question of where and how often stratospheric intrusions can reach the planetary boundary layer and to what extent STE contributes to total ozone levels at the surface is a topic of ongoing research (e.g. Davies and Schuepbach, 1994; Stohl et al., 2000; Vingarzan, 2004; Cooper et al., 2005; Trickl et al., 2010; Cristofanelli et al., 2010; Lefohn et al., 2011, 2012; Kuang et al., 2012; Lin et al., 2012).

The current study provides a global climatology of STE from 1979 to 2011 based on a refined version of the Lagrangian method introduced by Wernli and Bourqui (2002) and the state-of-the-art reanalysis data set ERA-Interim from the European Centre for Medium-Range Weather Forecasts (ECMWF). This methodology allows for study of the transport pathways from the stratosphere to the troposphere (STT) and from the troposphere to the stratosphere (TST). Of particular interest are so-called "deep" exchange events where stratospheric air, which typically is rich in ozone, reaches the planetary boundary layer (PBL) (deep STT) or potentially polluted air from the PBL is rapidly transported into the stratosphere (deep TST).

Climatologies using meteorological data with a spatial and temporal resolution high enough to capture important synoptic systems (e.g. Sprenger and Wernli, 2003; James et al., 2003b) nicely complement global-scale estimates (e.g. Holton et al., 1995) and synoptic-scale modelling case studies (e.g. Lamarque and Hess, 1994; Bourqui, 2006). The Lagrangian method used in this study also has several advantages over other methods such as the budget approach (Appenzeller et al., 1996), which does not allow for study of the transport pathways; the Eulerian Wei method (Wei, 1987), which additionally suffers from errors due to the cancellation of large terms (Wirth and Egger, 1999) and large sensitivity to errors in the input fields (Gettelman and Sobel, 2000); and isentropic trajectory calculations (Seo and Bowman, 2001), which are frequently limited to a few isentropes and thus miss a significant amount of exchange events (Sprenger and Wernli, 2003). A good overview of previous climatologies of STE, the methods used, and their limitations is given in the review paper of Stohl et al. (2003) and the studies of Wirth and Egger (1999) and Wernli and Bourqui (2002).

The tropopause definition used in our study is the combination of the \pm 2 pvu potential vorticity (PV) (Ertel, 1942) isosurfaces and the $380 \mathrm{~K}$ isentrope, which is a well-established definition for the dynamical tropopause (Hoskins et al., 1985; Holton et al., 1995) ( $1 \mathrm{pvu}=$ $\left.10^{-6} \mathrm{~K} \mathrm{~m}^{2} \mathrm{~kg}^{-1} \mathrm{~s}^{-1}\right)$. Since PV is conserved in adiabatic, frictionless flow, the dynamical tropopause is a generally well-defined continuous surface with a quasi-material character. Air parcels can only cross the dynamical tropopause if diabatic or other non-conservative processes such as friction change the PV (or the potential temperature $\Theta$ in the trop- ics). This definition captures the complex, three-dimensional structure of the tropopause which is often observed near jet streams, cyclones, and cut-off lows (e.g. Bithell et al., 1999) and enables the calculation of cross-tropopause fluxes in situations when other control surfaces such as the lapserate tropopause are discontinuous. Many other tropopause definitions exist (e.g. Hoinka, 1997), and evidently, fluxes across a control surface crucially depend on its definition (see Sect. 5).

This paper is structured as follows: we first describe the data set and the methodology in Sect. 2. Then we present the climatology of the cross-tropopause mass flux in Sect. 3 , followed by the results for the cross-tropopause ozone flux in Sect. 4. The sensitivity of our results to various parameters and the choice of control surface is explored in Sect. 5. In Sect. 6, we discuss caveats of the methodology, compare our results to the findings of Sprenger and Wernli (2003) and other studies, and elaborate some regional aspects. Finally, we present our conclusions in Sect. 7.

\section{Data and methodology}

\subsection{Overview}

The reanalysis data set ERA-Interim from the ECMWF (Simmons et al., 2006; Dee et al., 2011) is continuously updated and covers the time from 1 January 1979 to the present day. Our analysis covers the first $33 \mathrm{yr}$ from 1979 up to and including 2011. The primary analysis fields (e.g. wind and temperature) were interpolated on a regular grid with $1^{\circ}$ horizontal resolution and the secondary fields such as $\Theta$ and PV were then calculated on the original hybrid model levels as described in Sprenger and Wernli (2003). The Lagrangian methodology presented in Wernli and Bourqui (2002) and applied to the ERA-15 data set in Sprenger and Wernli (2003) was further developed and used to calculate mass and ozone fluxes across the tropopause, pressure surfaces in the middle and lower troposphere $(500,600,700$, and $800 \mathrm{hPa})$ and the top of the PBL.

This methodology is based on a large set of trajectories started every $24 \mathrm{~h}$ on a regular grid spanning the whole globe between 650 and $50 \mathrm{hPa}$. The spacing of this grid is approximately $\Delta x=80 \mathrm{~km}$ in the horizontal and $\Delta p=30 \mathrm{hPa}$ in the vertical. In the tropics (between $30^{\circ} \mathrm{S}$ and $30^{\circ} \mathrm{N}$ ) the vertical grid spacing is $10 \mathrm{hPa}$ to accommodate for the typically slower vertical motion. The kinematic trajectories are calculated with the tool developed by Wernli and Davies (1997) using the three-dimensional wind fields from ERA-Interim.

Only trajectories that cross the tropopause $(2 \mathrm{pvu} / 380 \mathrm{~K})$ within the first $24 \mathrm{~h}$ are selected, and these are extended for 4 days forward and backward, resulting in a total length of 9 days. To remove trajectories representing transient exchanges, a two-way minimum residence time $(\tau)$ criterion is applied. This criterion requires that each trajectory spends at 
least $\tau=48 \mathrm{~h}$ on one side of the tropopause before crossing and then remain on the other side for at least $48 \mathrm{~h}$. Thus, only "significant" exchange events are taken into account. Each trajectory represents a fixed amount of mass given by the spacing of the starting grid: $\Delta m \approx \frac{1}{g}(\Delta x)^{2} \Delta p \approx 6.52 \times$ $10^{11} \mathrm{~kg}$ (in the extratropics). The mass flux across a surface is thus calculated by counting the number of crossing trajectories and multiplying by $\Delta m$. Note that trajectories started in the tropics have a smaller $\Delta p$ and thus a smaller $\Delta m$. The STT ozone flux is calculated accordingly with $\Delta m_{\mathrm{O}_{3}} \approx \frac{M_{\mathrm{O}_{3}}}{M_{\mathrm{d}}} \cdot \Delta m \cdot\left[\mathrm{O}_{3}\right]$, where $M_{\mathrm{O}_{3}}$ and $M_{\mathrm{d}}$ represent the molecular weights of ozone and dry air, respectively. The ozone concentration at the crossing, $\left[\mathrm{O}_{3}\right]$, is obtained from linear spatial and temporal interpolation to the trajectory location.

The two main enhancements of this methodology introduced in the current study are a more elaborated distinction between the troposphere and the stratosphere using a 3-D labelling algorithm and an altered definition of vertically deep exchange events, which is more relevant for understanding surface ozone concentrations.

\section{$2.2 \quad 3-D$ labelling}

Outside the tropics, an STE event can in principle be detected as a transition of the trajectory's PV from below to above 2 pvu ( -2 pvu in the Southern Hemisphere) or vice versa. However, there are diabatically produced PV structures in the troposphere and low-level PV anomalies due to friction, for instance near mountains. If their PV value exceeds 2 pvu, they may be mistaken as stratospheric air. We have therefore used a refined version of the 3-D labelling algorithm introduced in Sprenger et al. (2003) to separate tropospheric and stratospheric air more objectively. This algorithm not only combines the $\pm 2 \mathrm{pvu}$ and the $380 \mathrm{~K}$ criterion but also checks the connectivity of grid points with $|\mathrm{PV}|>2$ pvu to the stratosphere or the surface and assigns labels from 1 to 5 to every grid point, as illustrated in Fig. 1. The label 2 (stratosphere) is initialized above $380 \mathrm{~K}$ and iteratively given to all horizontally, vertically, or diagonally connected grid points with $|\mathrm{PV}|>2 \mathrm{pvu}$. Analogously, the label 1 (troposphere) is initialized at the lowest model level at all points where $|\mathrm{PV}|<2$ pvu and distributed to all connected grid points. Grid points with $|\mathrm{PV}|>2$ pvu which were not reached by the label 2 are assigned the label 3 (three-dimensional stratospheric cut-offs or diabatically produced PV anomalies) and analogous for tropospheric cut-offs (label 4). STE events are thus identified as transitions from label 2 to 1 (STT) and 1 to 2 (TST) within $24 \mathrm{~h}$.

Over Greenland and especially over Antarctica, very stable air masses just above the surface often have high PV values. Because these PV anomalies are of different nature than stratospheric cut-offs, they are assigned a separate label 5, which is initialized at all grid points on the lowest model

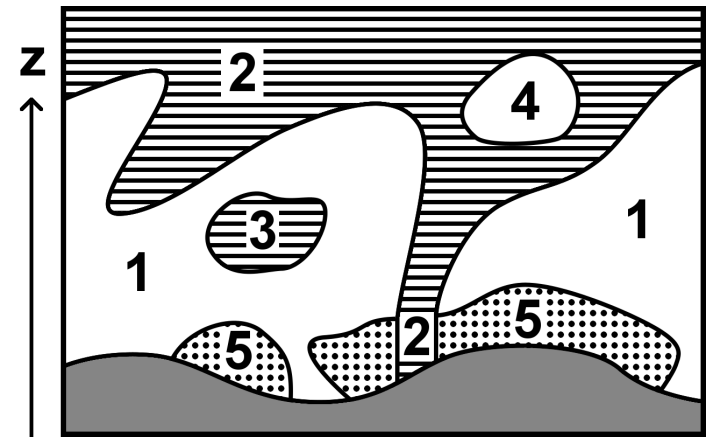

Fig. 1. The 3-D labelling algorithm assigns labels from 1 to 5 to every grid point based on PV, $\Theta$, and the "connectivity" to the top of the ERA-Interim data set or the surface. The labels used are as follows: 1, troposphere; 2 , stratosphere; 3 , stratospheric cut-off in the troposphere or other cyclonic PV anomaly not connected to the stratosphere; 4 , tropospheric cut-off in the stratosphere; and 5, surface-bound PV anomaly. In the special cases where label 2 merges with label 5 , the label 2 is attributed to grid points in the vertical column below the area of contact. The label 2 can only propagate horizontally if the contact occurs in the upper half of the troposphere (in this vertical column). See Sect. 2.2 for a more detailed description of this algorithm.

level with $|\mathrm{PV}|>2 \mathrm{pvu}$. If such a surface-bound PV anomaly comes in contact with a low tropopause, distinguishing between the anomaly and the stratosphere requires an additional criterion. Instead of the threshold in specific humidity chosen by Sprenger et al. (2003) and Gray (2003), which is problematic in the case of very dry air masses above Antarctica, our new criterion is of geometric nature. We impose that label 2 can always propagate vertically and overrides label 5 . As a consequence, all grid points with $|\mathrm{PV}|>2$ pvu in the vertical column below an area of contact between label 2 and label 5 are given the label 2 . The horizontal propagation of label 2 in such cases, however, is limited to the upper half of the troposphere (calculated for every column) which prevents the label 2 from being spread over a large area near the surface. The very few cases where a trajectory originating within a surface-bound PV anomaly (label 5) meets such a "stratospheric funnel" (label 2) and then enters the troposphere (label 1) are filtered out by requiring that the label remain constant along the trajectory for $48 \mathrm{~h}$ before and after the tropopause crossing.

\subsection{Deep exchange events}

The importance of vertically deep exchange events stems from the rapid exchange between the stratosphere and the PBL and their particular impact on atmospheric chemistry. In previous studies, deep exchange events were defined as trajectories with a maximum pressure greater than $700 \mathrm{hPa}$ (Wernli and Bourqui, 2002; Sprenger and Wernli, 2003) or 


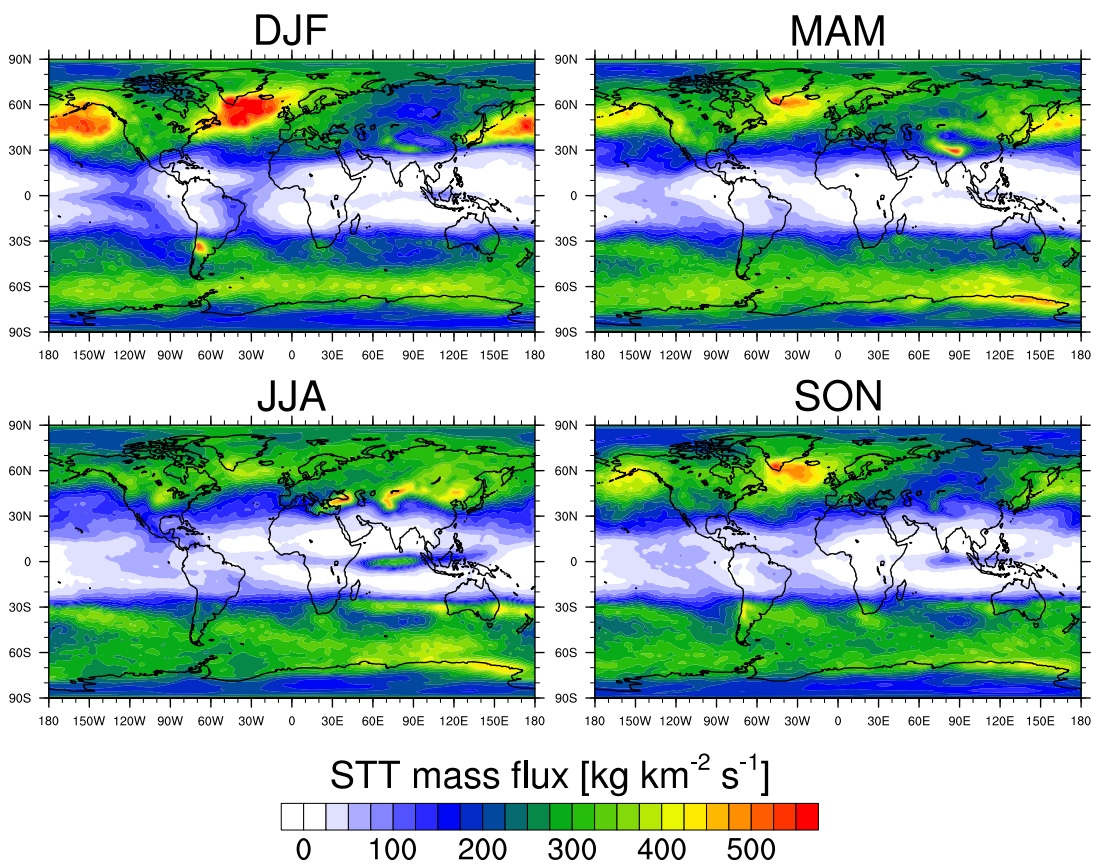

Fig. 2. Seasonally averaged STT mass flux for 1979-2011 (DJF: December, January, February; MAM: March, April, May; JJA: June, July, August; SON: September, October, November).

a minimum height lower than $3 \mathrm{~km}$ (James et al., 2003b). These are crude approximations to the PBL height, which ignore its diurnal cycle and geographical variation and limit the investigation to areas without high topography. Therefore, in this study, we use the PBL height from ERA-Interim 6-hourly forecasts to identify deep exchange events. A trajectory is thus only selected as a deep exchange if its pressure exceeds the pressure at the PBL top at any time step after the exchange (for deep STT) or before the exchange (for deep TST). If multiple crossings of the PBL top occur along a trajectory, only the first one is selected for deep STT (and the last one for deep TST). The PBL height in the ECMWF model is determined as the height at which the bulk Richardson number reaches the critical value 0.25 , following Troen and Mahrt (1986). This typically selects the top of stratocumulus clouds but is closer to the cloud base in shallow convection situations (Dee et al., 2011). For the calculation of the deep STT ozone flux, the ozone concentration is kept constant along a trajectory after having crossed the tropopause since the ozone field in ERA-Interim agrees better with independent observations in the stratosphere than in the troposphere (Dragani, 2011), as further discussed in Sect. 6.3.

\section{STE climatology: mass flux}

The global mass fluxes in our study amount to $8.89 \times$ $10^{10} \mathrm{~kg} \mathrm{~s}^{-1}$ (STT) and $8.75 \times 10^{10} \mathrm{~kg} \mathrm{~s}^{-1}$ (TST), yielding a downward net flux of $1.33 \times 10^{9} \mathrm{~kg} \mathrm{~s}^{-1}$, which is roughly two orders of magnitude smaller than the gross flux $(\mathrm{STT}+\mathrm{TST})$. This net downward flux is further discussed in Sect. 3.5.

\subsection{Geographical distribution}

\subsubsection{Total STT mass flux}

The geographical distribution of the STT mass flux is shown in Fig. 2. In the Northern Hemisphere (NH), the storm tracks over the North Atlantic and North Pacific are the dominant regions for STT during all seasons (around $500 \mathrm{~kg} \mathrm{~km}^{-2} \mathrm{~s}^{-1}$; peak value in DJF: $625 \mathrm{~kg} \mathrm{~km}^{-2} \mathrm{~s}^{-1}$ ) except for JJA (around $\left.350 \mathrm{~kg} \mathrm{~km}^{-2} \mathrm{~s}^{-1}\right)$. This agrees well with previous findings (e.g. Sprenger and Wernli, 2003). The mountain chains in Asia such as the Himalayas (DJF, MAM), the Pamirs (DJF, MAM, JJA), and the Tian Shan (MAM, JJA) are also associated with an intense STT flux (above $450 \mathrm{~kg} \mathrm{~km}^{-2} \mathrm{~s}^{-1}$ ). The elevated STT flux over the north-central US, Anatolia, and the northern side of the Tibetan Plateau in JJA are likely due to intense tropopause folding activity (Sprenger et al., 2003).

In the Southern Hemisphere (SH), two zonal bands around 35 and $65^{\circ} \mathrm{S}$ show an enhanced STT mass flux. The band along the subtropical jet (STJ), where tropopause folds occur preferentially, is clearly visible in JJA with peaks over the east and west coasts of Australia and the northern Tasman Sea (around $425 \mathrm{~kg} \mathrm{~km}^{-2} \mathrm{~s}^{-1}$ ). In $\mathrm{SON}$ and DJF, the main peak is located over the Andes (reaching $500 \mathrm{~kg} \mathrm{~km}^{-2} \mathrm{~s}^{-1}$ ), and the southern tip of Africa shows elevated values (up 

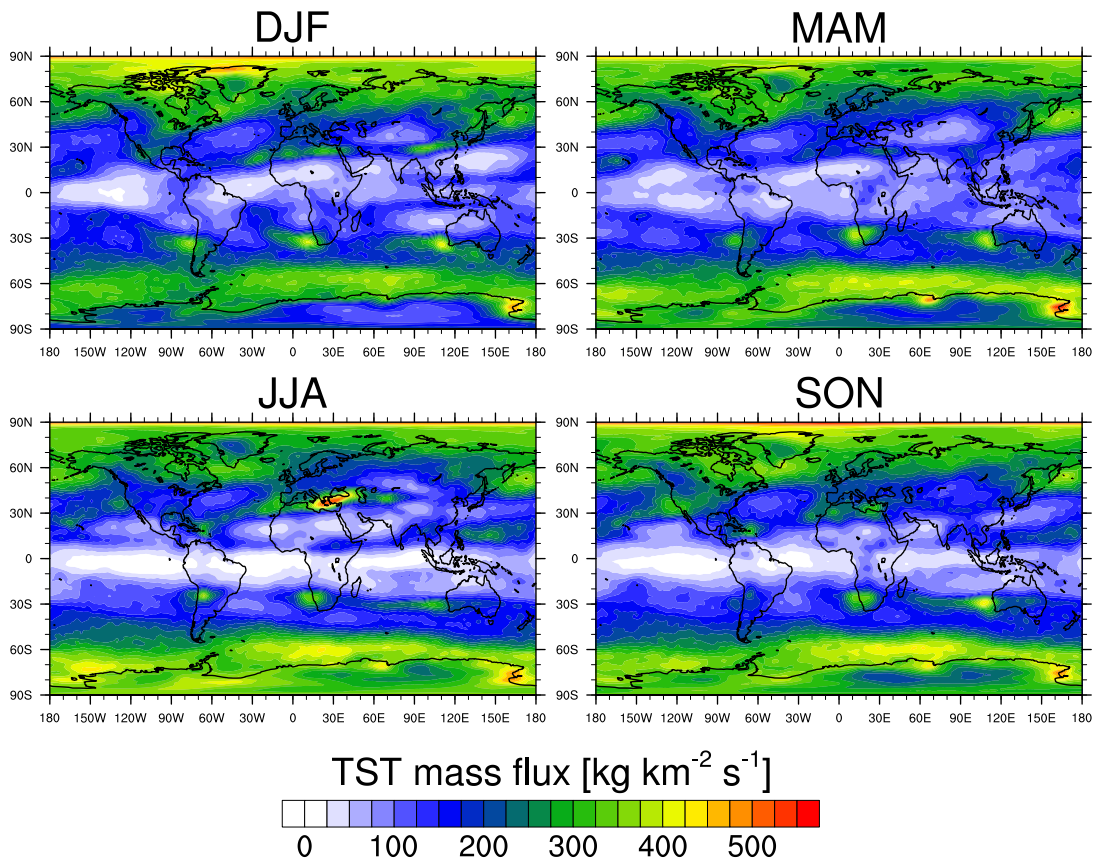

Fig. 3. Seasonally averaged TST mass flux for 1979-2011.

to $350 \mathrm{~kg} \mathrm{~km}^{-2} \mathrm{~s}^{-1}$ ) in all seasons. STT along the storm track over the Southern Ocean is quite uniform in SON and DJF and becomes more localized over Wilkes Land in East Antarctica during MAM and JJA (up to $450 \mathrm{~kg} \mathrm{~km}^{-2} \mathrm{~s}^{-1}$ ). This is also when the most deep tropopause folds are found in this region (Sprenger et al., 2003).

\subsubsection{Total TST mass flux}

The annually averaged TST mass flux (Fig. 3) mainly shows large values poleward of approximately $55^{\circ}$ latitude in both hemispheres and preferentially over the oceans and coastal regions. Distinct peaks are found along the north coast of Greenland (up to $475 \mathrm{~kg} \mathrm{~km}^{-2} \mathrm{~s}^{-1}$ in DJF and around $400 \mathrm{~kg} \mathrm{~km}^{-2} \mathrm{~s}^{-1}$ in MAM and SON) and along the coast of Antarctica, especially over Mac. Robertson land near $70^{\circ} \mathrm{E}$ (reaching $500 \mathrm{~kg} \mathrm{~km}^{-2} \mathrm{~s}^{-1}$ in MAM) and the Transantarctic Mountains around $165^{\circ} \mathrm{E}$ (peaking at $550 \mathrm{~kg} \mathrm{~km}^{-2} \mathrm{~s}^{-1}$ in MAM, around $475 \mathrm{~kg} \mathrm{~km}^{-2} \mathrm{~s}^{-1}$ in other seasons). As discussed above, the deep tropopause folding activity is high in these regions in JJA, but since it is very low in DJF, this cannot be the only explanation for the quasi-permanent peaks observed.

In the subtropics, notable peaks are found over the eastern Mediterranean and Anatolia (up to $525 \mathrm{~kg} \mathrm{~km}^{-2} \mathrm{~s}^{-1}$ in JJA), the regions upstream of the continents around $30^{\circ} \mathrm{S}$ (all seasons), and over northern Africa (JJA, SON, DJF). Tropopause folds are quite frequent in all these regions and are especially deep over Anatolia (Sprenger et al., 2003). The importance of the western Pacific for tropical TST during the Asian monsoon period is well known (e.g. Fueglistaler et al., 2004; Gettelman et al., 2004). Indeed, enhanced TST is visible on the eastern flank of the upper-level anticyclone in Fig. 3 in JJA and to a lesser extent also in SON.

\subsubsection{STT mass flux through pressure surfaces}

As mentioned in the Introduction, it is important to not only investigate the flux across the tropopause but also follow the STT air parcels as they descend into the troposphere. This is of course also true for TST air parcels in the stratosphere, but due to the focus of this study on quantifying the stratospheric contribution to tropospheric ozone, we only discuss STT here. In Fig. 4, the mass flux across four pressure surfaces is depicted and the areas with strongest fluxes across the tropopause are indicated with contours. For every trajectory, only the first crossing of a pressure surface is taken into account. One clearly visible feature is the equatorward transport of the air parcels as they descend. The peaks in the flux across the $700 \mathrm{hPa}$ surface are on average located $10-15^{\circ}$ closer to the Equator in the $\mathrm{NH}$ and approximately $20^{\circ}$ in the $\mathrm{SH}$ than the peaks in the flux across the tropopause. This is readily explained by quasi-isentropic transport on isentropes sloping downwards towards the Equator due to the strong baroclinicity in the extratropics.

The flux across the $700 \mathrm{hPa}$ surface is dominated by exchanges in the North Atlantic and North Pacific storm tracks, a zonal band around $40^{\circ} \mathrm{S}$ originating from exchanges along the storm track in the Southern Ocean and peaks over the south-central United States and central Europe. What can 


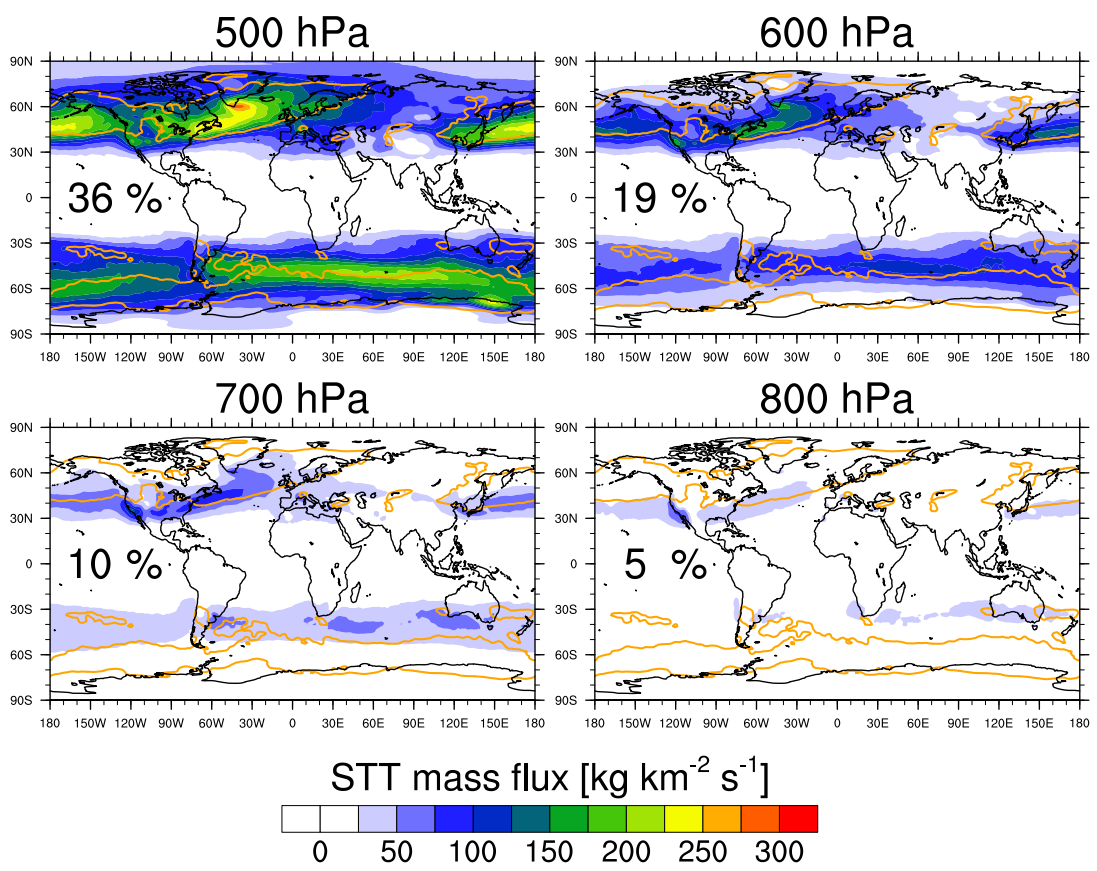

Fig. 4. STT mass flux through the 500, 600, 700, and $800 \mathrm{hPa}$ pressure surfaces of all STT events averaged over the period from 1979 to 2011 (annual mean). The orange contours indicate areas where the STT mass flux across the tropopause is greater than $300 \mathrm{~kg} \mathrm{~km}^{-2} \mathrm{~s}^{-1}$. The percentage values indicated in the panels are calculated with respect to the globally integrated STT mass flux across the tropopause.

also be seen from these plots is that only a small amount of exchange events are vertically deep and reach a pressure of $700 \mathrm{hPa}$ or more (roughly $10 \%$ ). Also, for obvious reasons, there is no flux below $700 \mathrm{hPa}$ in areas with high orography such as the Himalayas. This illustrates the need for a refined criterion for deep exchange events, compared to Wernli and Bourqui (2002), Sprenger and Wernli (2003) and James et al. (2003b), that is also applicable in mountain areas.

\subsubsection{Mass flux from deep STT events into the PBL}

The especially interesting cases where stratospheric air reaches the PBL within a few days (deep STT) are shown in Fig. 5. The flux into the PBL is depicted in colours and the contours indicate where the flux across the tropopause is largest. Note that these contours do not directly correspond to the flux shown in Fig. 2 because only the subset of deep exchanges is taken into account here.

Since the largest boundary layer heights in ERA-Interim are found over subtropical desert areas (Von Engeln and Teixeira, 2013), it is clear that dry regions with high orography in these latitudes facilitate the transport from the stratosphere into the PBL and vice versa. Indeed, in both hemispheres, the subtropics around $30^{\circ}$ and especially mountain ranges near these latitudes are preferred regions of deep STT into the PBL. Very distinct maxima are found over the Rocky Mountains and the northern Sierra Madre (up to $220 \mathrm{~kg} \mathrm{~km}^{-2} \mathrm{~s}^{-1}$ in MAM) as well as over the Himalayas and the Tibetan Plateau (up to $250 \mathrm{~kg} \mathrm{~km}^{-2} \mathrm{~s}^{-1}$ in DJF and MAM).

The latter maximum is explained by the mechanism described above, which allows for a near-horizontal exchange of air between the stratosphere and the PBL. The high orography combined with intense heating leads to very high boundary layers, especially in the semiarid western part of the Tibetan Plateau and before the onset of the Asian monsoon (Yanai and Li, 1994; Yang et al., 2004; Chen et al., 2013). The air masses transported to this region cross the tropopause over an area stretching from northern Africa to the Pamirs. The peak over the Rocky Mountains is of different nature since both the topography and the PBL height are lower, such that there more vertical transport is needed in order to reach the PBL. The air masses cross the tropopause at the end of the North Pacific storm track and slide down the isentropes in a southeastward direction. This roughly corresponds to the situation shown by Sprenger and Wernli (2003, their Fig. 6a).

The storm tracks in the North Atlantic and North Pacific are also areas of enhanced deep STT, which is especially interesting because of the relatively shallow marine PBL. The entrance into the PBL is shifted approximately $20^{\circ}$ equatorward from the crossing of the tropopause due to transport along sloping isentropes as discussed before. This implies that even areas south of $30^{\circ} \mathrm{N}$ can be affected by stratospheric air (Cooper et al., 2005). Central Europe, northern Africa, and the Middle East are mainly affected in DJF and 

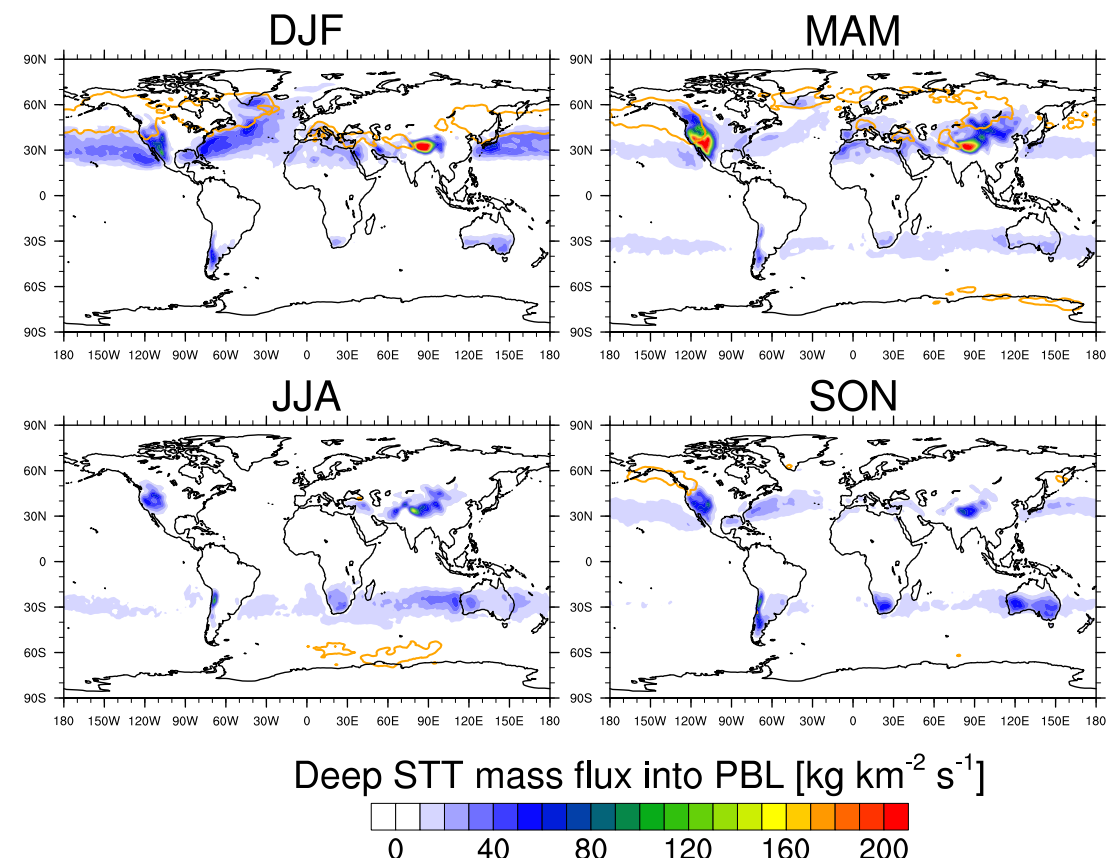

Fig. 5. Seasonally averaged deep STT mass flux into the PBL for 1979-2011. The orange contours indicate areas where the mass flux across the tropopause due to deep STT is higher than $25 \mathrm{~kg} \mathrm{~km}^{-2} \mathrm{~s}^{-1}$.

MAM. We can confirm the finding of Sprenger and Wernli (2003) that a significant amount of air entering the PBL over and near the Mediterranean crosses the tropopause over the European Alps (their Fig. 6c). In MAM and JJA, there is also some deep STT reaching the PBL around the Hindu Kush, the Pamirs, the Altay Mountains, the Mongolian Plateau, and Gobi Desert. In the SH, most deep STT occurs in the subtropics in JJA and SON with peaks over the Andes (between 20 and $30^{\circ} \mathrm{S}$ ), the Karroo in South Africa, and both over and upstream of Australia.

Note that Fig. 5 is comparable with the "destinations" plot in Sprenger and Wernli (2003, their Fig. 5a). An obvious example of how the $700 \mathrm{hPa}$ criterion (used in the above study) and the PBL criterion (used here) for deep exchanges differ is the fact that the peak over the Tibetan Plateau in DJF is only visible in our study.

\subsubsection{Mass flux from deep TST events out of the PBL}

The flux of air masses out of the PBL that will reach the stratosphere within 4 days (deep TST) is shown in Fig. 6. Clearly, the entrance of the North Atlantic and North Pacific storm tracks are preferred areas of deep TST in DJF (up to $125 \mathrm{~kg} \mathrm{~km}^{-2} \mathrm{~s}^{-1}$ ) and to a lesser extent in MAM and SON. The air masses then cross the tropopause roughly $20^{\circ}$ poleward, which agrees very well with the findings of Sprenger and Wernli (2003) in DJF (their Fig. 6d).

The Tibetan Plateau emerges as a distinct peak in DJF $\left(350 \mathrm{~kg} \mathrm{~km}^{-2} \mathrm{~s}^{-1}\right)$ and especially in MAM $\left(450 \mathrm{~kg} \mathrm{~km}^{-2} \mathrm{~s}^{-1}\right)$. A closer look at the data reveals that these air masses mainly cross the tropopause over the northwestern Pacific (contour in Fig. 6), which corresponds to a fast upward and long-range eastward transport of approximately $6500 \mathrm{~km}$ in less than 4 days. In JJA, this eastward transport is slower and the air masses also cross the tropopause over eastern Siberia and the northwestern Pacific around $50^{\circ} \mathrm{N}$.

The Rocky Mountains and the adjacent areas to the east are regions with a strong deep TST flux out of the PBL during nearly the whole year with a maximum in MAM $\left(175 \mathrm{~kg} \mathrm{~km}^{-2} \mathrm{~s}^{-1}\right)$ and a minimum in DJF. Additional analysis reveals that most of this air crosses the tropopause over the Hudson Bay in JJA and SON, whereas this peak is shifted south over the Great Lakes area and the Canadian Shield in DJF and MAM (cf. contours in Fig. 6).

We only see a weak signal of deep TST mass flux out of the PBL over China's east coast in MAM and JJA, and no signal over India and Indochina. This is interesting because several studies (e.g. Berthet et al., 2007; Chen et al., 2012) found intense deep TST activity in this area, which is strongly affected by anthropogenic emissions. A possible reason for this discrepancy is that Chen et al. (2012) used FLEXPART (Stohl et al., 2005, with parameterized convective transport) and considered longer timescales. Our approach focuses on relatively fast (within 4 days) transport by the grid-scale winds, which is likely to underestimate deep convective transport over continents in summer. The different 


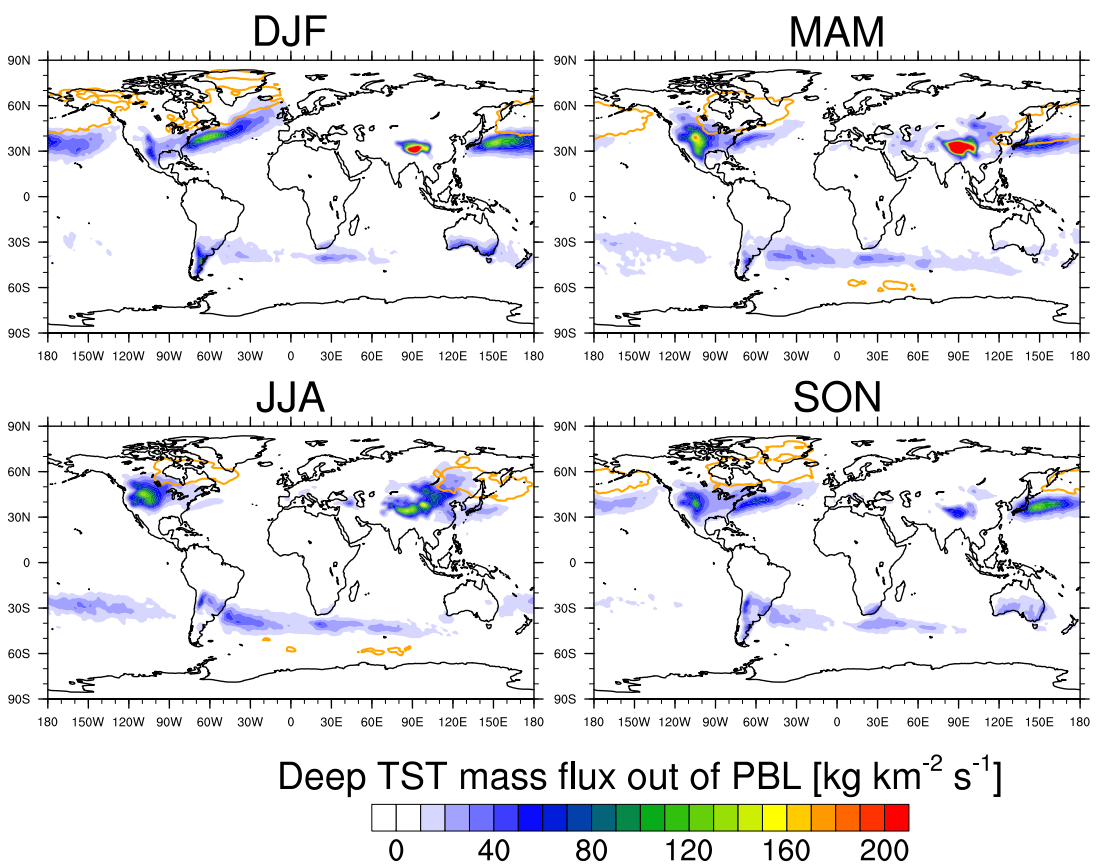

Fig. 6. Seasonally averaged deep TST mass flux out of the PBL for 1979-2011. The orange contours indicate areas where the mass flux across the tropopause due to deep TST is higher than $25 \mathrm{~kg} \mathrm{~km}^{-2} \mathrm{~s}^{-1}$.

timescales used could also explain why the signal over northern Africa and the Arabian Peninsula visible in Berthet et al. (2007), where 30-day backward trajectories were calculated, is not present in our study.

In the $\mathrm{SH}$, the flux out of the PBL occurs predominantly between 20 and $50^{\circ} \mathrm{S}$. In SON and DJF, mainly the continents are affected, especially the region east of the southern Andes (up to $110 \mathrm{~kg} \mathrm{~km}^{-2} \mathrm{~s}^{-1}$ ) and the south coasts of Africa and Australia. In MAM and JJA, areas of intense deep TST fluxes are also found along the storm track over the Southern Ocean.

\subsection{Zonally integrated fluxes}

The meridional profiles of the zonally integrated values of STT, TST, and net (STT-TST) mass fluxes are shown in Fig. 7. Also depicted are the fluxes due to deep exchange events across the tropopause (TP) and the top of the PBL. Overall, there is remarkably little interannual variability, indicating very robust patterns.

\subsubsection{All exchanges}

The STT mass flux features a broad peak in the extratropics in both hemispheres. The distribution in the $\mathrm{NH}$ is of triangular shape with a maximum around $45^{\circ} \mathrm{N}$, whereas the $\mathrm{SH}$ exhibits a smeared-out double-peak structure caused by the superposition of two separate peaks near $30^{\circ} \mathrm{S}$ (main peak, due to the STJ) and near $60^{\circ} \mathrm{S}$ (secondary peak, due to the

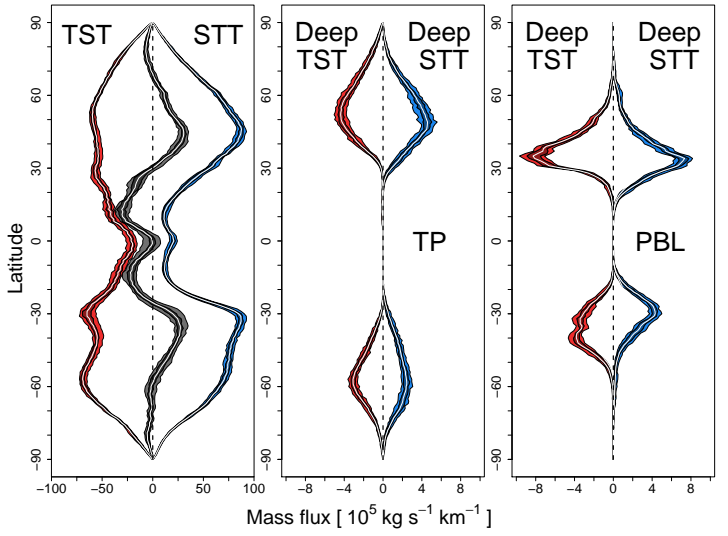

Fig. 7. Meridional distribution of zonally integrated crosstropopause mass fluxes averaged from 1979 to 2011 . The STT, TST, and net (STT-TST) fluxes are shown on the left, and the STT and TST fluxes of deep exchanges only are shown in the middle. The right panel shows the fluxes of deep exchanges into (STT) and out of (TST) the PBL. STT fluxes are shown positive (blue), TST fluxes negative (red) and the net flux is shown in grey. The dashed vertical line at zero mass flux is used for visual guidance and facilitates the identification of areas with net upward or downward flux in the left panel. The shading shows the 5th and 95th (light) and the 25th and 75th (dark) percentiles of the annual values, and the white line is the mean value of the $33 \mathrm{yr}$ investigated. 


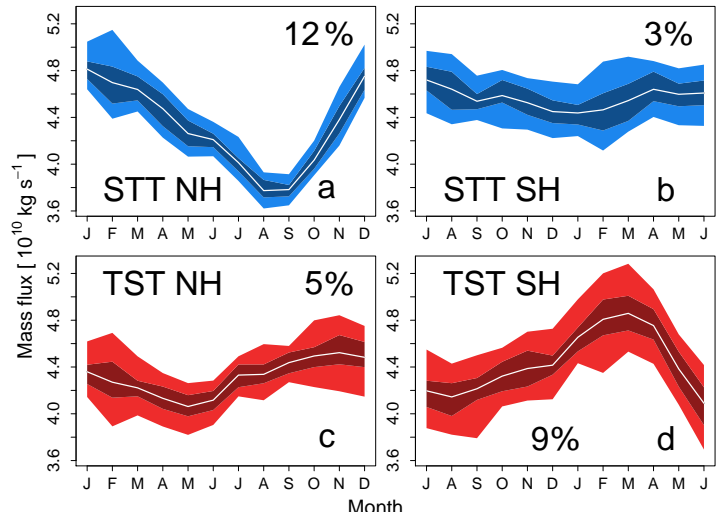

Fig. 8. Seasonal cycle of hemispherically integrated STT (blue, top) and TST (red, bottom) mass fluxes by all exchange events in the NH (left) and SH (right) averaged from 1979 to 2011. The shading shows the 5th and 95th (light) and the 25th and 75th (dark) percentiles of the monthly values, and the solid white line is the mean value of the $33 \mathrm{yr}$. The seasonality is quantified by $S=\frac{\max -\min }{\max +\min }$, where max and min denote the maximum and minimum value of the mean cycle. Percentages of $S$ are shown in the individual plots.

storm track over the Southern Ocean, cf. Fig. 2). The secondary peak in this superposition is clearly visible in the seasonal averages and especially in DJF, when the main peak is comparatively low (not shown).

The TST mass flux shows a complex structure consisting of two main peaks and one secondary peak in both hemispheres: one main peak is found around $55^{\circ} \mathrm{N}$ and $60^{\circ} \mathrm{S}$ due to exchanges along the storm tracks (North Atlantic, North Pacific, Southern Ocean) and the other around $30^{\circ} \mathrm{N}$ and $30^{\circ} \mathrm{S}$ mainly due to exchanges near the STJ in the Mediterranean $(\mathrm{NH})$ and upstream of the continents ( $\mathrm{NH}$ and $\mathrm{SH}$ ) (cf. Fig. 3). In addition, there are two secondary tropical peaks around $10-15^{\circ}$ latitude in both hemispheres that are better visible in the seasonal averages and are smeared out by the meridional displacement of the Intertropical Convergence Zone (not shown).

The net mass flux is directed downward between 30 and $70^{\circ} \mathrm{N}$ and between 25 and $60^{\circ} \mathrm{S}$ and upward in the tropics between $25^{\circ} \mathrm{S}$ and $25^{\circ} \mathrm{N}$, except for a narrow band with nearzero net fluxes right at the Equator. Poleward of $70^{\circ} \mathrm{N}$ and $60^{\circ} \mathrm{S}$, the net flux is very small and directed upward, which agrees well with earlier studies (Juckes, 1997; Sprenger and Wernli, 2003, their Fig. 8).

\subsubsection{Deep exchanges}

Deep exchange trajectories cross the tropopause in the extratropics and low polar regions in both directions (STT and TST) and hemispheres (NH and SH). The distributions for deep STT and deep TST indeed look very similar. The deep TST peak is shifted about $5^{\circ}$ to the north with respect to the peak of deep STT in the $\mathrm{NH}$, whereas in the SH the peaks are

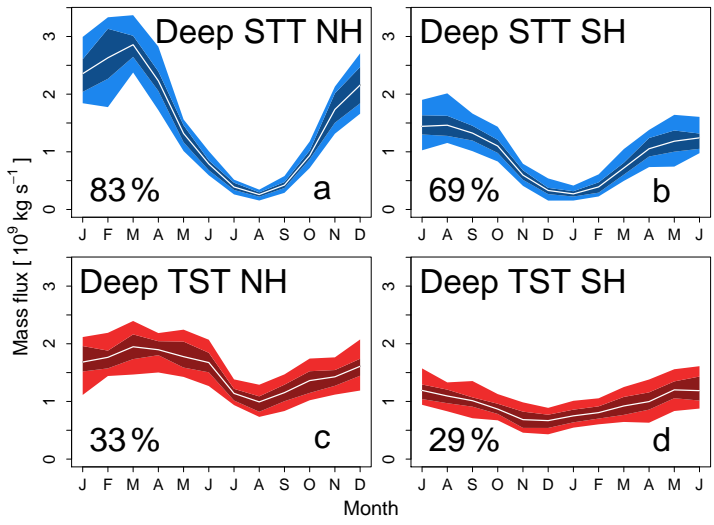

Fig. 9. Seasonal cycle of hemispherically integrated deep STT (blue, top) and deep TST (red, bottom) mass fluxes in the NH (left) and SH (right) averaged from 1979 to 2011. The shading shows the 5th and 95th (light) and the 25th and 75th (dark) percentiles of the monthly values, and the solid white line is the mean value of the $33 \mathrm{yr}$. The seasonality is quantified and displayed as in Fig. 8.

very well aligned. The peaks in the $\mathrm{SH}$ are located around $60^{\circ} \mathrm{S}$, whereas the ones in the $\mathrm{NH}$ are located closer to the Equator, around $50^{\circ} \mathrm{N}$. The peaks of the mass flux into (STT) and out of (TST) the PBL are shifted, relative to the peaks of the TP crossings, towards the Equator by roughly $15^{\circ}$ in the $\mathrm{NH}$ and $20-30^{\circ}$ in the $\mathrm{SH}$. This shift is qualitatively in line with the slope of the isentropes, which is particularly steep in the NH storm track regions. Note also that, in particular in the SH, the shift is larger for STT than TST, indicating that deep STT occurs on dry isentropes, whereas deep TST can be associated with saturated motion on moist isentropes from the PBL to the upper troposphere.

An interesting hemispheric difference is the greater intensity of deep STT and deep TST in the NH. The reason for this might be the more vigorous PBL dynamics over the more abundant NH continents.

\subsection{Seasonal cycles}

Monthly averages of STT and TST mass fluxes are calculated for the $33 \mathrm{yr}$ covered in this climatology. As a simple measure of the seasonality within a year, we consider the quotient $S=\frac{\max -\min }{\max +\min }$, where max and min denote the maximum and minimum averaged monthly values of the averaged annual cycle. This measure is essentially the ratio of the amplitude of the cycle and its mean value, such that $S=1$ for a cycle with a minimum value of zero.

\subsubsection{All exchanges}

The seasonal cycle of the STT mass flux (Fig. 8a, b) has a pronounced sawtooth-like shape in the NH with a maximum in winter (DJF), when the cyclonic activity over the North Pacific and North Atlantic is greatest, and a minimum 
around August and September. The minimum value is approximately $22 \%$ smaller than the peak value and the seasonality as defined above is $S=12 \%$. In the SH (Fig. 8b), the seasonal cycle is more sinusoidal in shape and much weaker ( $S=3 \%$ ) but its timing is roughly the same as in the $\mathrm{NH}$ with a peak in winter (July) and a minimum in summer (December and January).

The seasonal cycle of the TST mass flux in the NH (Fig. 8c) also shows a rather sinusoidal cycle with a maximum in November and a minimum in May $(S=5 \%)$. In the SH (Fig. 8d), a clear peak in March dominates the seasonal cycle. It is followed by a steep drop between April and June (due to fewer exchanges in the tropics) and a slow increase throughout the rest of the year $(S=9 \%)$.

Note that in contrast to the NH and SH cycles of STT, which peak in the same season, the $\mathrm{NH}$ and $\mathrm{SH}$ cycles of TST have quite different timing. In the $\mathrm{NH}$, the maximum in TST is reached in late autumn, whereas in the SH, TST peaks in early autumn, corresponding to a shift of two months. The minima, on the other hand, occur nearly in the same month, namely in May ( $\mathrm{NH}$, late spring) and June (SH, early winter).

In the NH, the STT and TST cycles are shifted by two to four months with TST occurring earlier in the year than STT. In the SH, the cycles of STT and TST are nearly reversed with the minimum of TST being close to the maximum of STT and vice versa. This asynchronous behaviour indicates that different meteorological phenomena contribute to the peaks in STT and TST.

The comparison of our seasonal cycles to previous studies is not straightforward because some authors used either a different tropopause definition (Schoeberl, 2004) or investigated only the extratropics (Sprenger and Wernli, 2003; James et al., 2003a), or even both (Olsen et al., 2004). Our results also do not fully agree with the classical study of Appenzeller et al. (1996), in which the net mass flux was found to have maxima in May (NH) and June ( $\mathrm{SH}$ ) and minima in September (NH) and October (SH). Our net mass flux (not shown) has broad maxima between January and March (NH) and June and August (SH) and minima in September (NH) and February (SH). The timing of our minimum in the $\mathrm{NH}$ and maximum in the SH thus agrees nicely with the mentioned previous studies, and both our maximum in the $\mathrm{NH}$ and minimum in the $\mathrm{SH}$ are, although not being the main peaks, clearly visible in Appenzeller et al. (1996). When we restrict our analysis to the extratropics, as done in Sprenger and Wernli (2003) and James et al. (2003a), we obtain a seasonal cycle whose timing agrees quite well with their results (not shown).

\subsubsection{Deep exchanges}

The seasonal cycle of the mass flux due to deep STT events is shown in Fig. 9. The cycle for deep STT is much more pronounced than the one for all exchanges and shows a more sinusoidal shape. The maxima occur in winter and early spring

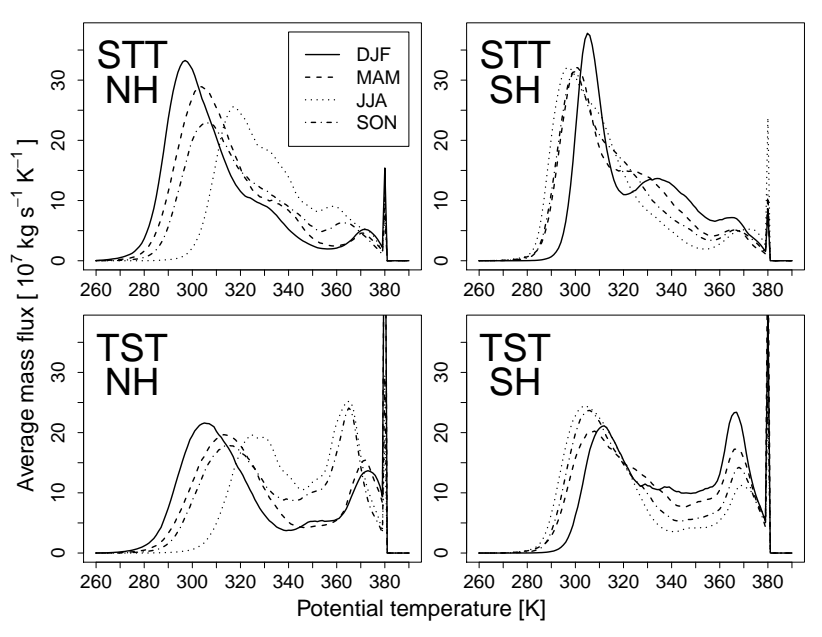

Fig. 10. Potential temperature distribution for STT (top) and TST (bottom) in the NH (left) and SH (right) averaged from 1979 to 2011. The seasons are indicated by different line patterns as listed in the legend.

(March in the NH and August in the $\mathrm{SH}$ ) and the minima in summer (August in the NH and January in the SH). The minimum in summer in the $\mathrm{NH}$ is less than $10 \%$ of the maximum value $(S=83 \%$ ), whereas in the SH the minimum reaches roughly $20 \%$ of the peak value $(S=69 \%$ ). Our seasonal cycle of deep STT mass flux in the NH agrees very well with the results of Sprenger and Wernli (2003) and James et al. (2003b).

The deep TST mass flux shows a less regular seasonal cycle in the NH: the flux is relatively constant from January to June, followed by a sharp decrease with a minimum in $\mathrm{Au}-$ gust, after which it steadily increases until January. In the SH, the deep TST mass flux shows a broad maximum between March and July and a minimum in December. The minimum is roughly $55 \%$ of the maximum value in both hemispheres, which shows that the seasonal cycle of deep TST ( $S=33 \%$ in the $\mathrm{NH}$ and $29 \%$ in the $\mathrm{SH}$ ) is much less pronounced than the one of deep STT. The deep TST mass flux in the NH is quite sinusoidal in Sprenger and Wernli (2003), whereas we observe a steep drop in early summer. This difference is due to the intense mass flux out of the PBL over the Tibetan Plateau in spring (not shown), which is not captured in the former study.

\subsection{Potential temperature distributions}

\subsubsection{All exchanges}

The distributions of $\Theta$ for all exchange events are depicted in Fig. 10. Due to the seasonal cycle of the isentropes, exchange in summer occurs on higher isentropes than in winter in both hemispheres and for both STT and TST. The $\Theta$ distributions for spring and autumn are fairly similar, except for TST in the NH, where SON shows a much higher peak 


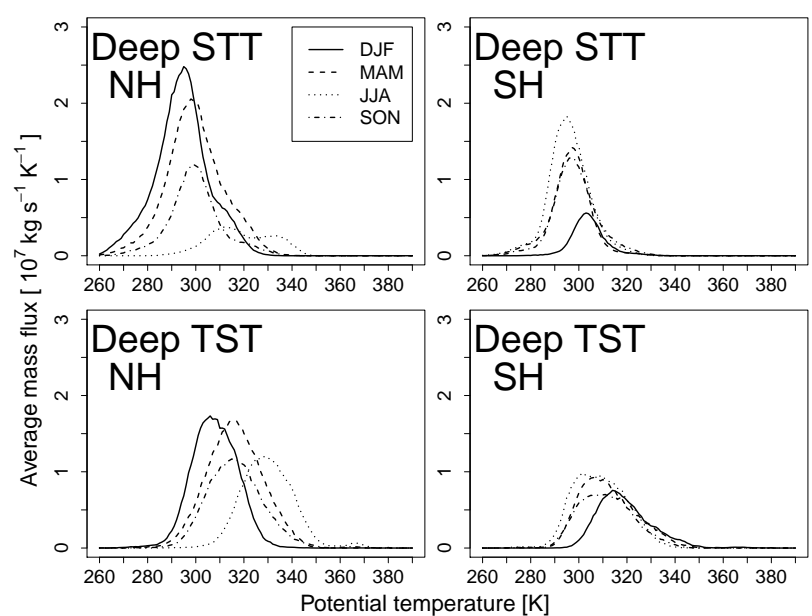

Fig. 11. Potential temperature distribution for deep STT (top) and deep TST (bottom) in the NH (left) and SH (right) averaged from 1979 to 2011 . The seasons are indicated by different line patterns as listed in the legend.

at $\Theta>340 \mathrm{~K}$ than MAM. The reason for this is the intense TST mass flux in the subtropics over the West Indies and the Caribbean in this season (not shown). There is a clear relationship between $\Theta$ and the latitude at the exchange location. In the tropics, exchanges occur at high potential temperatures above $350 \mathrm{~K}$, and as the tropopause slopes down towards the polar regions, exchanges in the extratropics occur at lower potential temperatures, mainly between 280 and $350 \mathrm{~K}$.

All distributions show a clear main peak below $350 \mathrm{~K}$, varying from $295 \mathrm{~K}$ (STT NH DJF) to $325 \mathrm{~K}$ (TST NH JJA). Additionally, a smaller peak between 330 and $340 \mathrm{~K}$ is visible for STT in the SH, especially in DJF, which is mainly due to exchanges over the Andes (see Fig. 2). The vast majority of exchange events above $350 \mathrm{~K}$ occur in the tropics and subtropics between $25^{\circ} \mathrm{S}$ and $30^{\circ} \mathrm{N}$ (STT) and between $35^{\circ} \mathrm{S}$ and $40^{\circ} \mathrm{N}$ (TST) (not shown).

As expected, TST is larger than STT at high $\Theta$, which concurs with a net upward transport in the tropics (cf. Fig. 7). Both for STT and TST, a prominent peak occurs at $380 \mathrm{~K}$ due to our tropopause definition. However, less than $1 \%$ (STT) and $3 \%$ (TST) of all exchanges take place at $380 \mathrm{~K}$. As expected, this peak is much stronger for TST than for STT and its geographical distribution is limited to a narrow band between $10^{\circ} \mathrm{S}$ and $10^{\circ} \mathrm{N}$ (not shown).

As already discussed in Sprenger and Wernli (2003), studies of STE that are limited to specific isentropes, such as 330 and $350 \mathrm{~K}$ (Seo and Bowman, 2001), capture only a fraction of all STE events and might produce a seasonal cycle that is not representative of total STE.

\subsubsection{Deep exchanges}

The $\Theta$ distributions for deep exchange events only are shown in Fig. 11. All peaks are sharper and limited to the region be-
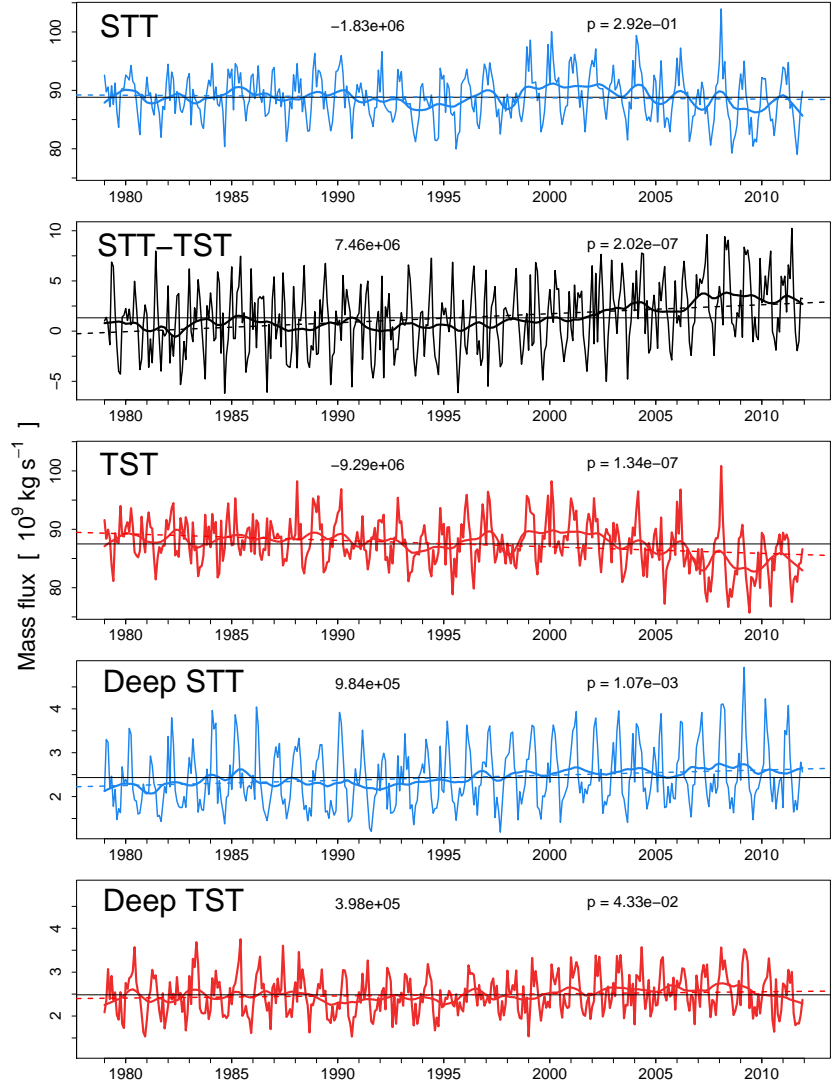

Fig. 12. Time series of globally integrated STT, net (STT-TST), TST, deep STT, and deep TST mass fluxes (monthly averages) from 1979 to 2011. The bold line is a 12-month moving average, the thin horizontal line (solid) is the mean value of the $33 \mathrm{yr}$, and the thin sloping line (dashed) is the fit from a linear regression over the whole period. The trends (top middle) in $\mathrm{kg} \mathrm{s}^{-1}$ month $^{-1}$ and $p$ values (top right) are shown within the individual figures.

low $350 \mathrm{~K}$, which is mainly due to the fact that very few deep exchange events occur in the tropics (cf. Fig. 7). A notable exception of the otherwise dominating single-peak structure is the deep STT distribution in the NH in JJA, which features a second, smaller peak around $330 \mathrm{~K}$ due to exchanges over the eastern Mediterranean and Anatolia (not shown). Again, the summer peaks are found at higher $\Theta$ than the winter peaks. The seasonal variation of the most likely $\Theta$ is larger in the $\mathrm{NH}(20-25 \mathrm{~K})$ than in the $\mathrm{SH}(10-15 \mathrm{~K})$.

\subsection{Time series}

The time series over the $33 \mathrm{yr}$ from 1979 to 2011 allows for study of the temporal evolution of STE over a longer period than the previously longest climatologies of STE, which covered the $15 \mathrm{yr}$ from 1979 to 1993 (Sprenger and Wernli, 2003; James et al., 2003b). For both STT and TST mass fluxes (Fig. 12), there is no trend discernible from 1979 to 2000 (in agreement with the findings of Sprenger 

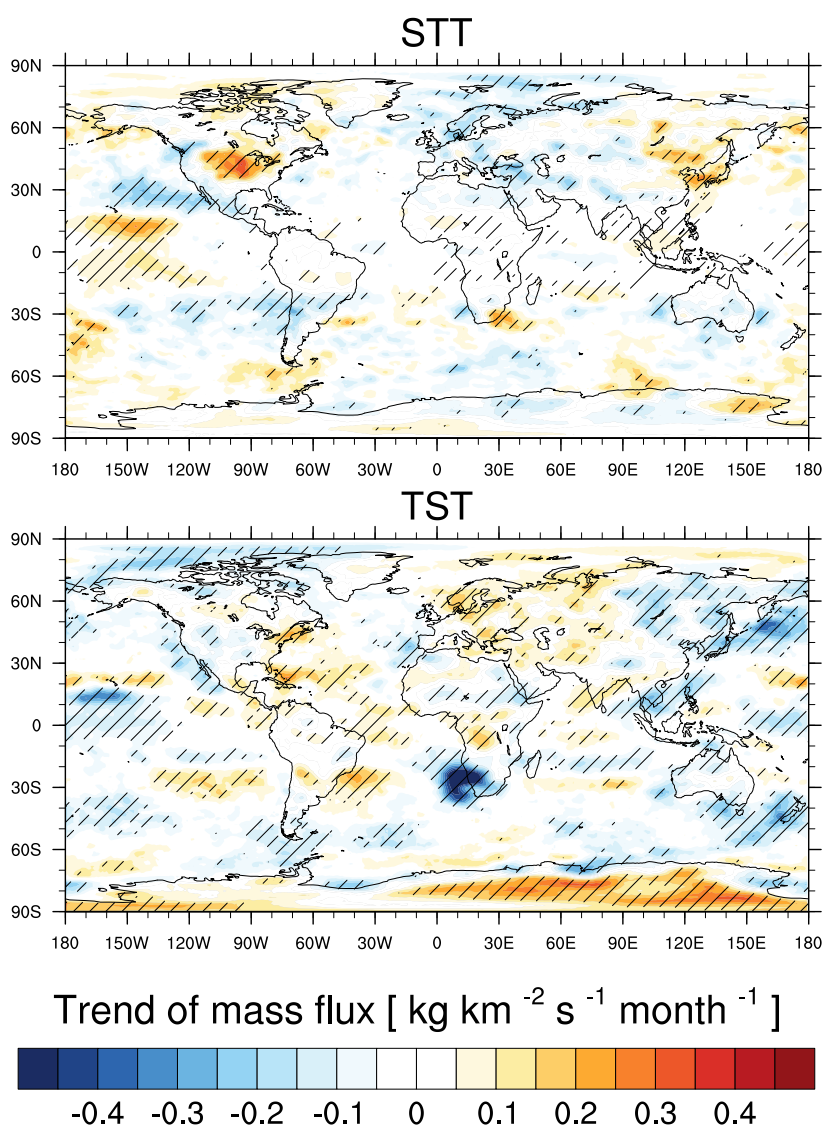

Fig. 13. Trends of STT (top) and TST (bottom) mass flux from 1979 to 2011. Linear regression is applied to monthly averages at every grid point, and regions where the trends are significant on a $1 \%$ level are dashed. The trend west of South Africa is approximately $-0.75 \mathrm{~kg} \mathrm{~km}^{-2} \mathrm{~s}^{-1}$ month $^{-1}$.

and Wernli (2003) for the ERA-15 period); thereafter both fluxes decline. The upward flux declines more strongly than the downward flux, resulting in a small increase in the net downward flux after 2000. Linear regression analysis for the whole time series yields highly significant $\left(p\right.$ value $\sim 10^{-7}$ ) trends for TST $\left(-9.29 \times 10^{6} \mathrm{~kg} \mathrm{~s}^{-1} \mathrm{month}^{-1}\right)$ and STT-TST $\left(7.46 \times 10^{6} \mathrm{~kg} \mathrm{~s}^{-1}\right.$ month $\left.^{-1}\right)$.

Since our study covers the whole globe, the non-zero global net downward mass flux has two possible interpretations: either the real net mass flux is zero and our result is due to numerical and methodological errors or the mass of the troposphere is increasing. The latter case would go along with a rise in tropopause heights which was reported in previous studies (e.g. Steinbrecht et al., 1998; Seidel and Randel, 2006; Schmidt et al., 2008). To further analyse this, we have calculated the area-weighted average pressure at the tropopause and the mass of the troposphere for every 6-hourly time step of ERA-Interim from 1979 to 2011. Linear regression analysis reveals highly significant $\left(p<2 \times 10^{-16}\right)$ trends of $-0.050 \pm 0.016 \mathrm{hPayr}^{-1}$ and
$2.843 \pm 0.083 \times 10^{14} \mathrm{~kg} \mathrm{yr}^{-1}$, in agreement with the studies mentioned above. This calculation thus suggests that the nonzero net downward mass flux is not a numerical artefact.

In addition to the trends of globally integrated mass fluxes, we have also analysed local trends. To this end, at every grid point $\left(1^{\circ} \times 1^{\circ}\right)$, time series of monthly averaged mass fluxes from 1979 to 2011 are used to perform a linear regression. As can be seen from Fig. 13, there are large differences between regions. While the STT mass flux shows no significant trend globally (see above and Fig. 12), significant $(p<0.01$, dashed areas in Fig. 13) and comparatively strong trends are found in many regions. The most intense positive trend is observed over central North America $\left(0.38 \mathrm{~kg} \mathrm{~km}^{-2} \mathrm{~s}^{-1}\right.$ month $^{-1}$, accompanied by a zonally aligned dipole structure over the North Pacific of magnitude $\pm 0.25 \mathrm{~kg} \mathrm{~km}^{-2} \mathrm{~s}^{-1} \mathrm{month}^{-1}$ ), indicative of an equatorward shift. Negative trends are most notably found over Anatolia, the southwestern tip of Scandinavia, and the Andes around $30^{\circ} \mathrm{S}$ (approximately $-0.30 \mathrm{~kg} \mathrm{~km}^{-2} \mathrm{~s}^{-1}$ month $^{-1}$ ).

The geographical distribution of trends in TST mass flux (bottom plot in Fig. 13) shows significant and strong positive trends over Antarctica, especially on its eastern side (up to $0.32 \mathrm{~kg} \mathrm{~km}^{-2} \mathrm{~s}^{-1}$ month $^{-1}$ ), even stronger negative trends over the northwestern Pacific (up to $-0.41 \mathrm{~kg} \mathrm{~km}^{-2} \mathrm{~s}^{-1}$ month $^{-1}$ ), and southwest of southern Africa (up to $-0.76 \mathrm{~kg} \mathrm{~km}^{-2} \mathrm{~s}^{-1}$ month $^{-1}$ ). The dipole structure over the North Pacific is again visible but the sign is reversed when compared to the STT mass flux trend. These zonally aligned dipole structures can also be found over the South Pacific and the Indian oceans, indicating a systematic poleward shift of the TST mass flux in the subtropics. The reason for these patterns is not clear and thus requires more detailed future investigation.

Both the globally integrated deep STT and deep TST mass fluxes increase over time (see Fig. 12). The trend obtained from linear regression analysis for the whole time series is more than twice as strong and much more significant for the deep STT mass flux $\left(9.84 \times 10^{5} \mathrm{~kg} \mathrm{~s}^{-1}\right.$ month $^{-1}$, $p \approx 0.001)$ than for the deep TST mass flux $(3.98 \times$ $10^{5} \mathrm{~kg} \mathrm{~s}^{-1}$ month $\left.^{-1}, p \approx 0.04\right)$. These trends are heavily influenced by positive trends over central and western North America (see Fig. S1 in the Supplement), with magnitudes of approximately $0.13 \mathrm{~kg} \mathrm{~km}^{-2} \mathrm{~s}^{-1}$ month $^{-1}$ and $0.17 \mathrm{~kg} \mathrm{~km}^{-2} \mathrm{~s}^{-1}$ month $^{-1}$ for deep STT and deep TST, respectively.

\section{Ozone flux into the troposphere}

Geographical and seasonal variations in ozone concentrations at the tropopause (Fig. 14) are large and have a strong impact on the ozone flux across the tropopause. The tropics show high ozone mixing ratios (around $140 \mathrm{ppbv}$ ) in all seasons, and values below $60 \mathrm{ppbv}$ can be found in the polar regions in winter. In the extratropics, there are especially high 

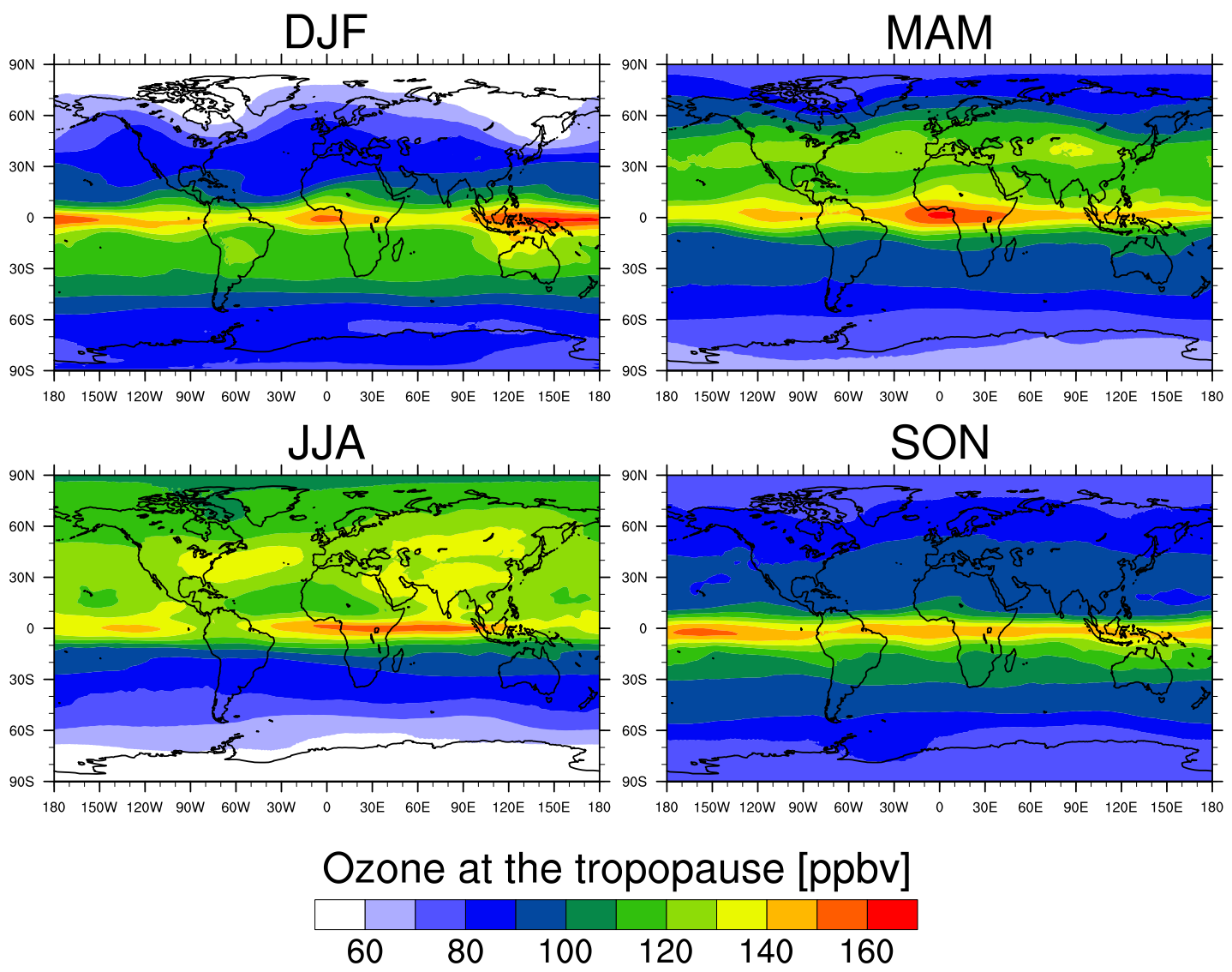

Fig. 14. Seasonally averaged ozone mixing ratios per volume (ppbv) at the 2 pvu/380 K dynamical tropopause for $1979-2011$.

ozone concentrations at the tropopause in boreal spring and summer over the eastern US, the North Atlantic, the Middle East, and large parts of central Asia. In this section, due to the importance of investigating the stratospheric influence on near-surface ozone concentrations, we focus on the STT ozone flux. A brief discussion of the TST ozone flux can be found in Sect. 6.3.

The globally integrated STT ozone flux calculated in our study amounts to $420 \mathrm{Tg} \mathrm{yr}^{-1}$, which is within the estimates from models (556 $\pm 154 \mathrm{Tg} \mathrm{yr}^{-1}$; Stevenson et al., 2006) and observations (550 $\pm 140 \mathrm{Tg} \mathrm{yr}^{-1}$; Solomon et al., 2007). All calculations with the ozone field of ERA-Interim of course crucially depend on its quality. Dragani (2011) found that overall the ozone field agrees well with independent observations and performs better than in the earlier ERA-40 reanalysis. The relative errors in total column ozone are within $\pm 2 \%$ between $50^{\circ} \mathrm{S}$ and $50^{\circ} \mathrm{N}$, but the vertical profiles show errors of up to $20 \%$ in the lower stratosphere. Therefore, our results have to be interpreted with these limitations in mind.

\subsection{Geographical distribution}

The geographical distribution of the STT ozone flux through the tropopause is shown in Fig. 16. Areas of intense STT mass flux such as the storm tracks in the North Atlantic, the North Pacific, and the Southern Ocean also tend to show elevated values of the STT ozone flux. Nevertheless, there are some differences when comparing the mass flux (Fig. 2) with the ozone flux (Fig. 16) that originate from the strong seasonal and geographical variation of ozone at the tropopause (Fig. 14). In DJF, the ozone concentrations over the NH storm tracks are rather small, such that the dominant peak in ozone flux is located over the Andes in the $\mathrm{SH}$ (nearly $240 \mathrm{~kg} \mathrm{~km}^{-2}$ month $^{-1}$ ), where tropopause ozone concentrations are nearly twice as high. The peak over southern Greenland in the mass flux in MAM and SON is less prominent in the ozone flux due to the low ozone concentrations in this region. In JJA, the same areas show high mass and ozone fluxes (e.g. central North America, Anatolia, Pamirs, Tian Shan, northern China, Korea), with peaks up to $300 \mathrm{~kg} \mathrm{~km}^{-2}$ month $^{-1}$. The JJA ozone flux is dominant in the $\mathrm{NH}$, whereas the mass flux is more balanced between the hemispheres, a consequence of the strong hemispheric contrast in ozone concentration at the tropopause. An additional peak in the STT ozone flux is found along the Equator over the Indian Ocean (nearly $220 \mathrm{~kg} \mathrm{~km}^{-2}$ month $^{-1}$ ) due to the high ozone concentrations at the tropical tropopause. 


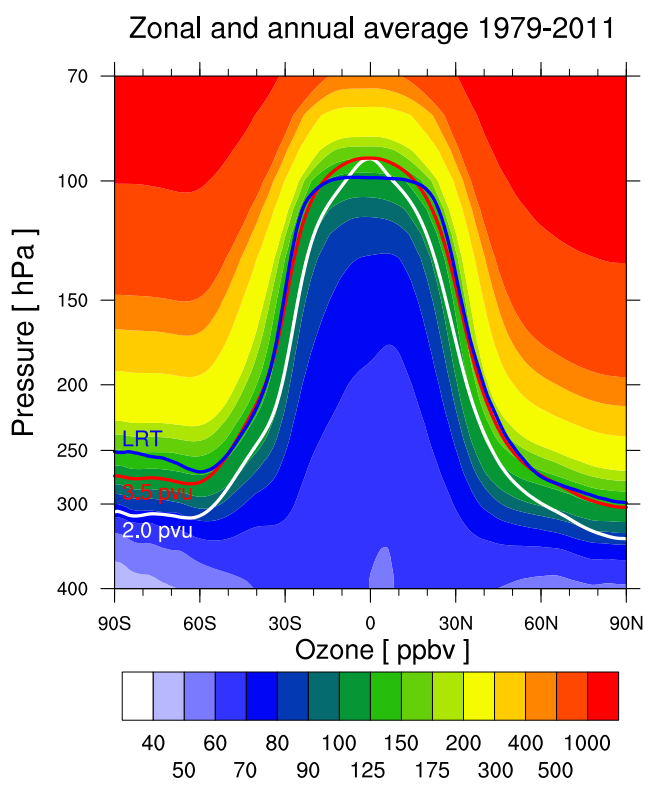

Fig. 15. Zonal and annual average of ozone mixing ratio and different tropopause definitions in ERA-Interim for 1979-2011. The blue, red, and white lines show the lapse-rate tropopause as defined by the WMO ("LRT"), the $3.5 \mathrm{pvu} / 380 \mathrm{~K}$ control surface ("3.5 pvu”) and the $2 \mathrm{pvu} / 380 \mathrm{~K}$ dynamical tropopause ("2.0 pvu”), respectively. Note the non-linear colour scale.

The global peaks of the STT ozone flux are thus found over the Andes around $35^{\circ} \mathrm{S}$ in DJF, over the Himalayas and the southern side of the Tibetan Plateau in MAM (up to $260 \mathrm{~kg} \mathrm{~km}^{-2}$ month $^{-1}$ ), and over central North America, Anatolia, the Pamirs, Tian Shan as well as large parts of eastern Asia in JJA (also up to $290 \mathrm{~kg} \mathrm{~km}^{-2}$ month $^{-1}$ ). These findings are consistent with the studies of Hsu et al. (2005) and Tang et al. (2011).

The geographical distribution of the deep STT ozone flux into the PBL shown in Fig. 17 indicates the regions where surface ozone levels are most likely affected by stratospheric intrusions. Western North America (in MAM) and the Tibetan Plateau (in DJF, MAM, and JJA) are the global hotspots with peaks values of more than $120 \mathrm{~kg} \mathrm{~km}^{-2}$ month $^{-1}$. For the calculation of this flux, the ozone concentration was kept constant within the troposphere (that is, any loss due to chemical processes and mixing was neglected) and therefore these values provide an upper boundary estimate. Nevertheless, our findings are in agreement with observational studies in these areas, which find a significant stratospheric influence (e.g. Langford et al., 2009; Cristofanelli et al., 2010; Lefohn et al., 2011, 2012; Lin et al., 2012).

\subsection{Seasonal cycle}

The seasonal cycle of the STT ozone flux (top row in Fig. 18), with $S=25 \%$ in the NH and $S=13 \%$ in the SH, shows a very different pattern than the STT mass flux (top row in Fig. 8). Indeed, maxima of the ozone flux occur when the mass flux is nearly at its minimum and vice versa. The explanation for this result is that the ozone concentration at the tropopause during STT events (bottom row in Fig. 18) shows a nearly sinusoidal seasonal cycle with a maximum in summer (around $130 \mathrm{ppbv}$ in the $\mathrm{NH}$ and $105 \mathrm{ppbv}$ in the $\mathrm{SH}$ ) and a minimum in winter (around $75 \mathrm{ppbv}$ in the $\mathrm{NH}$ and $80 \mathrm{ppbv}$ in the $\mathrm{SH}$ ). Even though the mass flux in summer is about $20 \%$ smaller than in winter, the ozone concentration is around $65 \%$ larger and thus overcompensates for the reduction in mass flux. This can also be quantified in terms of the seasonality $S$ : for the STT mass flux, $S=12 \%$ in the NH and $S=3 \%$ in the SH (cf. Sect. 3.3), whereas the ozone concentrations at the tropopause have a larger seasonality, namely $S=25 \%$ in the NH and $S=13 \%$ in the SH.

In contrast to the total ozone flux, the ozone flux for deep exchange events only (middle row in Fig. 18) largely agrees in its timing with the mass flux (top row in Fig. 9). This is because the seasonality of the mass flux is large enough to dominate the ozone flux: its value in summer is reduced by approximately $90 \%$ compared to winter $(S=83 \%$ in the NH and $S=69 \%$ in the SH, cf. Sect. 3.3). The peak in the deep STT ozone flux is slightly shifted (one month later compared to the mass flux) in both hemispheres. This is due to the increase of ozone concentrations at the tropopause during spring (cf. bottom row in Fig. 18). A remarkable consequence is that while the seasonal cycle of deep STT is similar to the whole STT mass flux, this is not true for the ozone flux. In fact, the deep STT ozone flux is shifted by roughly 4 months with respect to the STT ozone flux and peaks in early spring.

\subsection{Time series}

The global STT ozone flux shown in Fig. 19 slightly increases from 1979 to late 1991. It then is reduced during $3 \mathrm{yr}$ and increased notably between 1994 and late 2001. Between early 2002 and mid-2003, there is a striking jump and the ozone flux is roughly halved. Afterwards, it recovers again in 2004, stays nearly constant for $4 \mathrm{yr}$, and begins to decrease slightly after 2009. Details on these spurious jumps and possible explanations are discussed in Sect. 6.3.

\section{Sensitivity studies}

As mentioned in the introduction, the results obtained in this study are sensitive to a range of parameters. The most important ones are the choice of the control surface, the resolution of the input data and of the trajectory starting grid, and the minimum residence time (Bourqui, 2006). To analyse this 

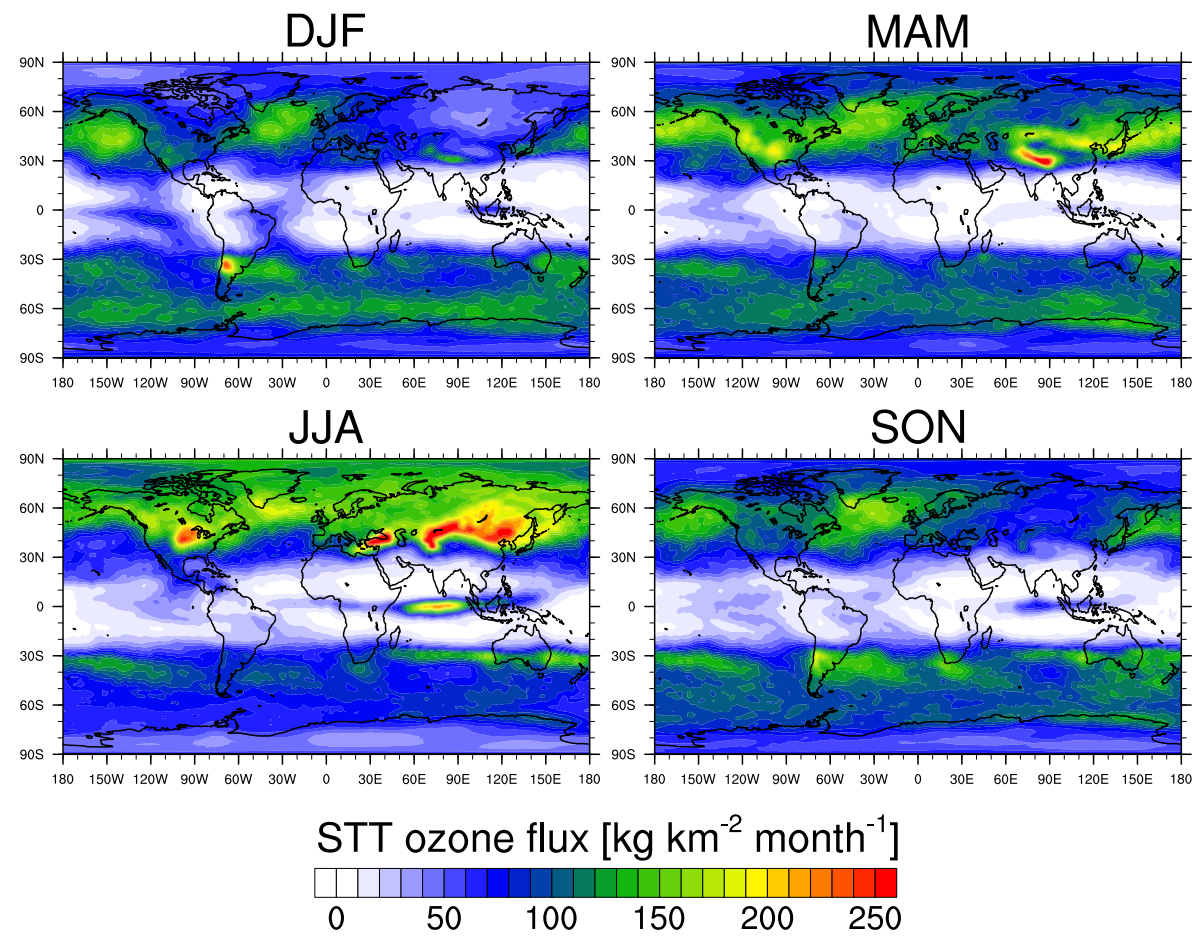

Fig. 16. Seasonally averaged STT ozone flux for 1979-2011.
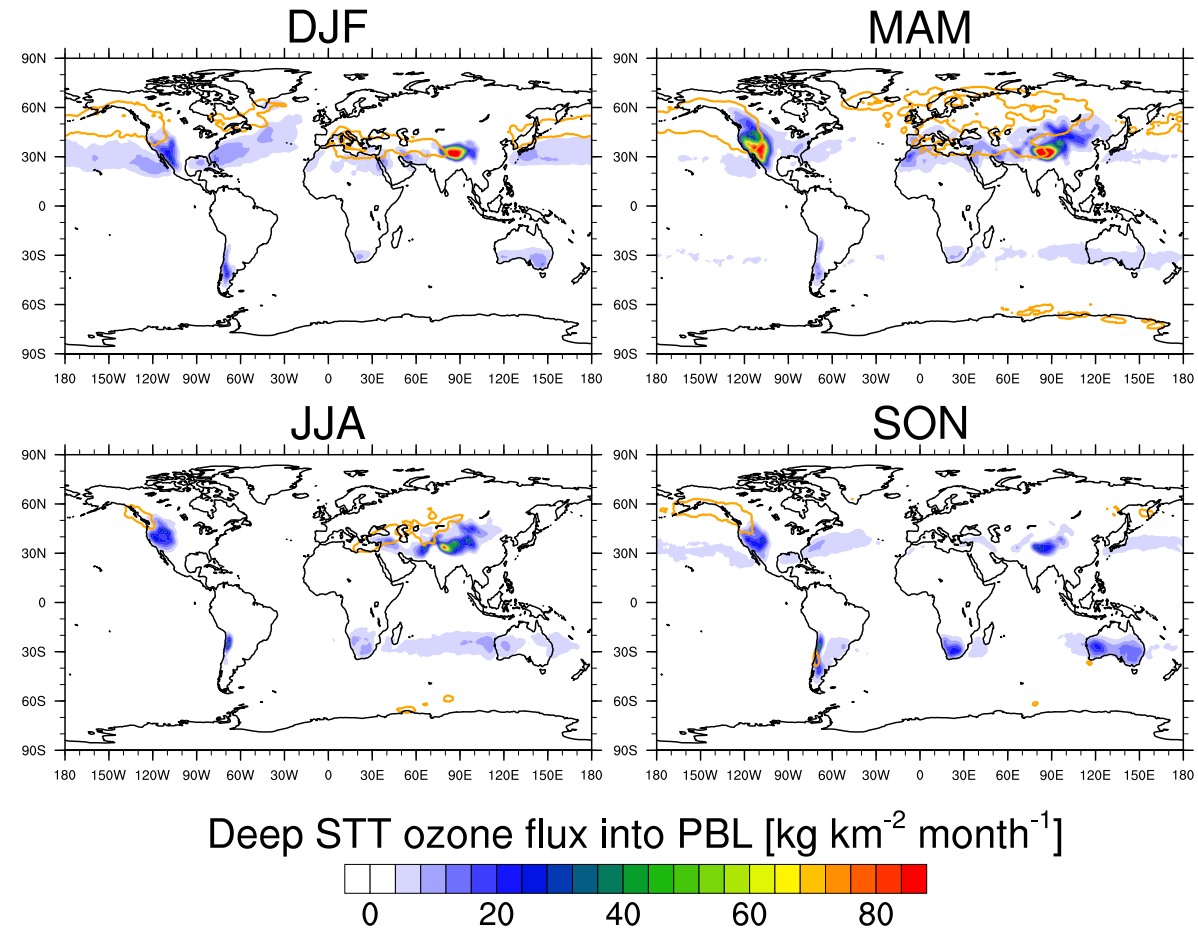

Fig. 17. Seasonally averaged deep STT ozone flux into the PBL for 1979-2011. For this calculation, the ozone concentration is kept constant along the trajectories after crossing the tropopause. The orange contours indicate areas where the ozone flux across the tropopause due to deep STT is higher than $7 \mathrm{~kg} \mathrm{~km}^{-2}$ month $^{-1}$. 


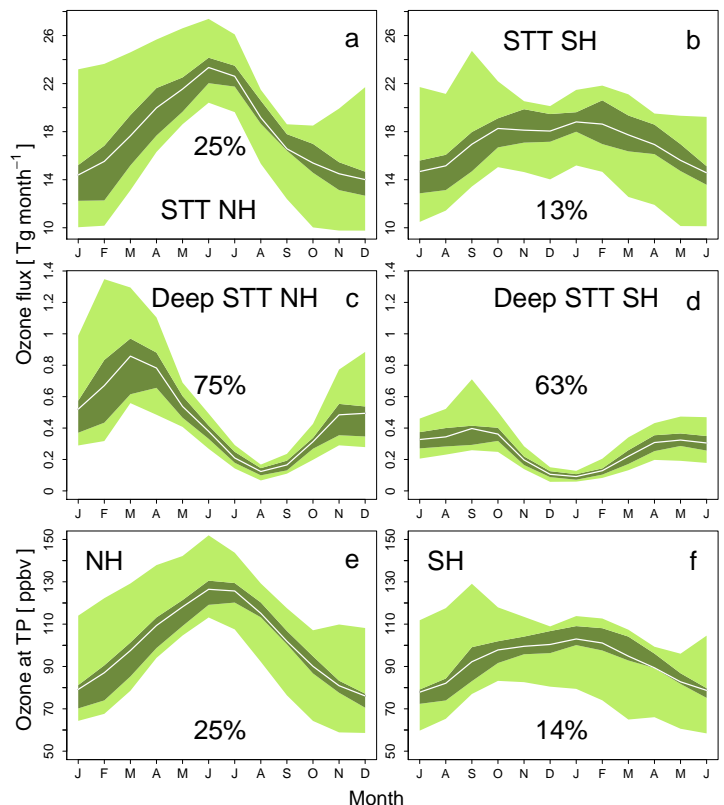

Fig. 18. Seasonal cycles of hemispherically integrated STT ozone flux (top) and deep STT ozone flux (middle) in the NH (left) and SH (right) averaged from 1979 to 2011. The bottom row shows the ozone mixing ratios at the $2 \mathrm{pvu} / 380 \mathrm{~K}$ dynamical tropopause. The shaded areas show 5th and 95th (light) as well as 25th and 75th (dark) quantiles of the monthly values. The solid white lines show the mean values of the $33 \mathrm{yr}$. The seasonality is quantified by $S=\frac{\max -\min }{\max +\min }$, where $\max$ and min denote the maximum and minimum value of the mean cycle. Percentages of $S$ are shown in the individual plots.

sensitivity, we calculated STE fluxes for the year 2010 using various combinations of the parameters mentioned above. Despite the noisiness of the results (due to the consideration of only one year), systematic effects are clearly visible.

\subsection{Choice of control surface}

STE fluxes critically depend on the choice of the control surface. To emphasize the quasi-material character of the dynamical tropopause, we use a fixed value of PV and note that the choice of the "best" PV value representing the transport barrier between the troposphere and the stratosphere is non-trivial and varies between different isentropes and seasons (Kunz et al., 2011). In our opinion, among all the possible control surfaces used to indicate the position of the tropopause, there exists no definition which is superior in all aspects and situations. The choice of a constant PV surface as the dynamical tropopause is meaningful and, when combined with the analysis of additional PV surfaces, allows for the three-dimensional structure of STE to be understood. Bourqui (2006) studied transport across PV surfaces ranging from 1 to 5 pvu but in this section, we focus on the "classical" values of 2.0 and 3.5 pvu. The " 3.5 pvu" STE data set is thus

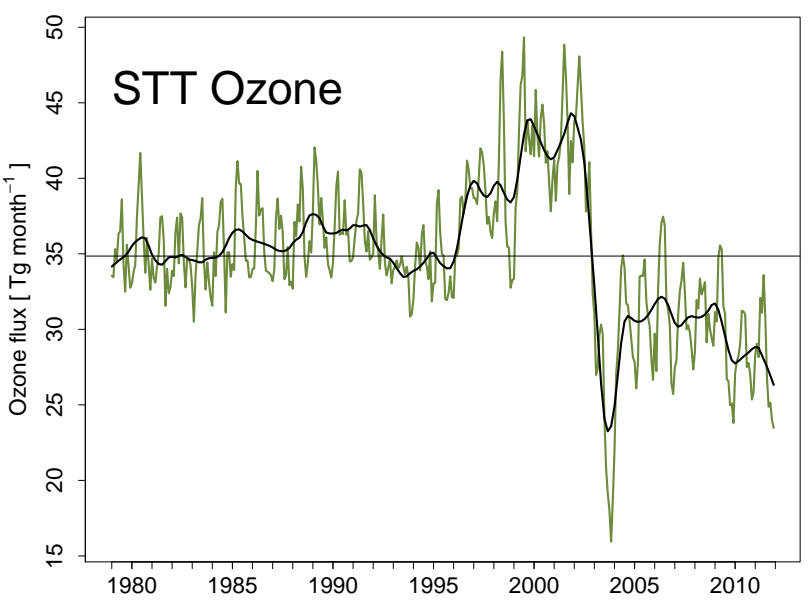

Fig. 19. Time series of the globally integrated STT ozone flux (monthly averages) from 1979 to 2011 . The bold line shows a 12month moving average and the mean value of the whole time series is indicated with a horizontal line.

obtained by choosing the combination of the \pm 3.5 pvu PV isosurfaces and the $380 \mathrm{~K}$ isentrope as the control surface. In the zonal average, this choice corresponds well to the lapserate tropopause as defined by the World Meteorological Organization (WMO, 1957; Hoinka, 1998). While this is also true for the temporally and zonally averaged ERA-Interim data set used in this study (see Fig. 15), the degree of agreement varies strongly for different synoptic flow systems.

While we clearly expect lower STE mass fluxes across the 3.5 pvu surface compared to the 2 pvu surface, the ozone mixing ratios are higher at the 3.5 pvu control surface (cf. Fig. 15) and it is thus not obvious which effect dominates the STT ozone flux. In the 3.5 pvu data set, the maximum STT mass flux is reduced by 39 and $36 \%$ in the $\mathrm{NH}$ and $\mathrm{SH}$, respectively (top row in Fig. 20). The maximum ozone mixing ratios, on the other hand, are higher by 38 and $48 \%$, respectively (bottom row in Fig. 20). Thus, the reduction in mass flux is partly compensated for by the increased ozone concentrations, leading to a weak reduction of the STT ozone flux in the 3.5 pvu data set $(11 \%$ in the $\mathrm{NH}$ and $13 \%$ in the $\mathrm{SH})$. The shape of the seasonal cycles is also very similar, with only a slight shift towards spring, which is more pronounced in the SH. This shift is clearly due to the shifted seasonal cycle of the ozone concentrations at the 3.5 pvu surface (bottom row in Fig. 20). The double-peak structure observed in the SH (Fig. 20d) is a particular feature of the considered year and is not visible in the $33 \mathrm{yr}$ climatology (see Fig. 18b).

For the subset of deep exchanges, the reduction in amplitude of the mass flux is much stronger. The maxima of the deep STT mass flux in the 3.5 pvu data set are reduced by $81 \%$ in the NH and $89 \%$ in the SH. Although not directly comparable, these results are in agreement with Bourqui (2006). This strong reduction dominates the compensating 


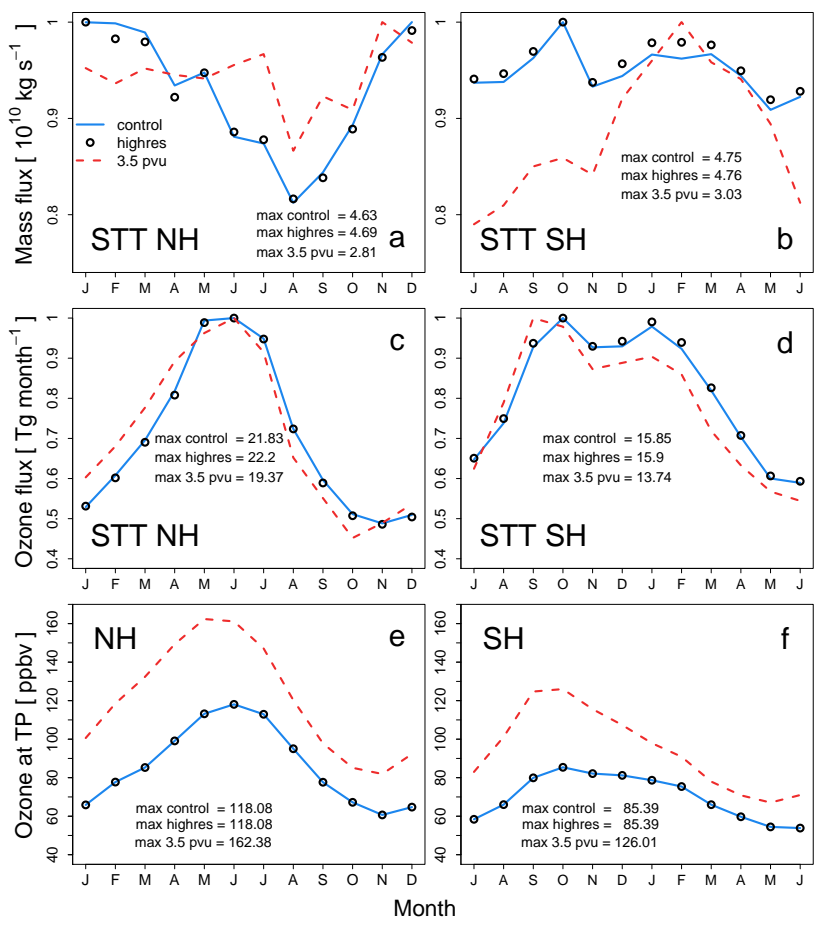

Fig. 20. Seasonal cycles of hemispherically integrated STT fluxes of mass (top) and ozone (middle) for the year 2010. The three different data sets ("control", "highres", and "3.5 pvu") are described in Sect. 5. In the bottom row, the average mixing ratio of ozone at the corresponding control surface is shown. The seasonal cycles are scaled to their maximum values shown within the individual figures, facilitating the comparison of amplitude and shape of the cycles.

effect of the higher ozone concentrations, leading to a reduction of more than $60 \%$ of the deep STT ozone flux (see Fig. S2 in the Supplement). The shapes of the seasonal cycles are very similar in both data sets. For TST, the situation is similar (see Fig. S3): the mass flux across the 3.5 pvu surface is reduced by approximately $34 \%$ in both hemispheres. The deep TST mass flux is strongly reduced by approximately $70 \%$. Although STT and TST are slightly differently affected by the change in control surface, the shape of the seasonal cycle of the net (STT-TST) mass flux is very similar in both data sets (see top row in Fig. S4) and the maximum values are reduced by $43 \%(\mathrm{NH})$ and $27 \%(\mathrm{SH})$.

We have further compared the geographical patterns of the STE mass fluxes by scaling the fluxes in both data sets to their respective global maximum (see Figs. S5-S8). Similarly to the hemispherically integrated values mentioned above, the global maxima of STT and TST mass fluxes are reduced by 27 and $44 \%$, respectively. Patterns of the STT mass flux are very similar for the two control surfaces, while for the TST mass flux, the relative importance of the tropics is strongly increased in the 3.5 pvu data set. This is due to the combination of identical STE fluxes across the $380 \mathrm{~K}$ isentrope in both data sets and an overall reduction of the STE

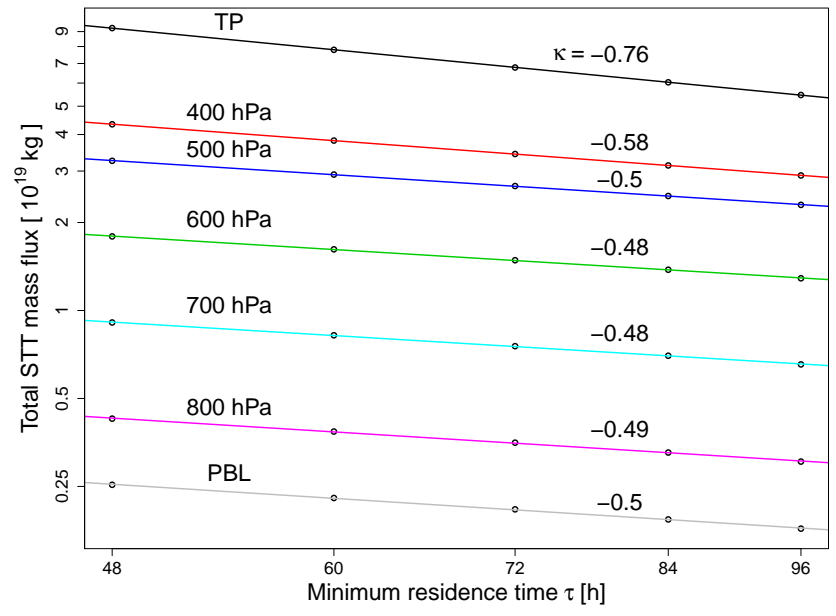

Fig. 21. Globally integrated STT mass flux across the tropopause, pressure surfaces from 400 to $800 \mathrm{hPa}$, and into the PBL averaged for 1979-2011. Note the double-logarithmic scale. The flux decreases with increasing minimum residence time threshold $\tau$ as a power law (that is, the flux is proportional to $\tau^{\kappa}$ ). The fitted exponents $\kappa\left(R^{2}>0.995\right.$ for all fits $)$ are listed adjacent to the corresponding curves.

flux across the higher PV isosurface. The fact that this effect is not visible for STT suggests that even in the tropics, STT occurs predominantly across the PV isosurface and not the $380 \mathrm{~K}$ isentrope, in agreement with the potential temperature distribution shown in Fig. 10.

The net upward transport in the polar regions across the 2 pvu tropopause (see Fig.7) is strongly reduced in the 3.5 pvu data set, mainly due to a relative decrease in TST compared to STT (see Fig. S9). This result is not in conflict with the large-scale subsidence in polar regions related to the Brewer-Dobson circulation, because the latter applies to pressure levels around $100 \mathrm{hPa}$ (Holton et al., 1995), while both PV isosurfaces used in this study are typically situated far below (between 275 and $350 \mathrm{hPa}$; see Fig. 15). Therefore, the reduced upward net flux in the 3.5 pvu data set indicates that the majority of TST events in polar regions are vertically shallow.

While the hemispherically integrated deep STE fluxes are reduced by more than $68 \%$ (see above), the global maxima are only reduced by 59 and $45 \%$ for deep STT and deep TST, respectively. The regions with strong deep STE flux across both the 2 pvu and the 3.5 pvu isosurfaces are predominantly located in the extratropics (not shown) and the location of the "hot spots" of deep STE flux across the PBL top is not affected by the different control surfaces used.

\subsection{Trajectory spacing}

We have studied the sensitivity of our method to the trajectory starting grid spacing by halving it in both the horizontal and vertical direction in the "highres" data set $(\mathrm{d} x=40 \mathrm{~km}$, 
$\mathrm{d} p=15 \mathrm{hPa}$ in the extratropics, and $\mathrm{d} p=5 \mathrm{hPa}$ in the tropics). As a consequence, the number of trajectories calculated is increased by a factor of 8 . The seasonal cycles are only very slightly affected by this increase in resolution (see Figs. 20, S2, and S3) and the geographical patterns are also robust (not shown). Thus the trajectory starting grid used in our study (see Sect. 2) is already sufficiently dense.

\subsection{Minimum residence time}

The quantitative results for all fluxes in this study strongly depend on the choice of the minimum residence time $\tau$ (Bourqui, 2001; Wernli and Bourqui, 2002; Bourqui, 2006). This is a fundamental property of any advective-diffusive flow across a control surface such as the tropopause (Hall and Holzer, 2003; Orbe et al., 2012). Clearly, the flux across a chosen surface decreases with increasing $\tau$ and vanishes for $\tau \rightarrow \infty$. In the limit $\tau \rightarrow 0$ the flux diverges due to molecular diffusion (Hall and Holzer, 2003).

We have studied the globally integrated fluxes of mass and ozone across the tropopause, pressure surfaces between 400 and $800 \mathrm{hPa}$, and the PBL top for $\tau$ between 48 and $96 \mathrm{~h}$. The results depicted in Fig. 21 show that the dependency on $\tau$ is, to very good approximation, a power law, i.e. proportional to $\tau^{\kappa}$. The fitted exponents $\kappa$ for the mass flux across the pressure surfaces below $500 \mathrm{hPa}$ and into the PBL are very close to $-0.5(-0.49 \pm 0.01)$, and for the $400 \mathrm{hPa}$ surface and the tropopause the values are $-0.58 \pm 0.01$ and $-0.76 \pm 0.02$, respectively. For the STT ozone, TST mass and TST ozone fluxes, the fitted exponents are of similar magnitude and can be found in Table 1 of the Supplement. The power law applies with remarkable precision: all coefficients of determination, $R^{2}$, are greater than 0.995 . These results are in agreement with theory, which suggests that for any advective-diffusive flow, the (mass) flux across a control surface such as the tropopause is proportional to $\tau^{-0.5}$ for small $\tau$ in the continuum limit (Hall and Holzer, 2003; Orbe et al., 2012). Note though that the $\tau$ used in these studies is only a one-sided criterion - that is, it is only required that the air parcels stay for at least $\tau$ in the stratosphere (in the case of STT) - whereas our minimal residence time $\tau$ is a twosided criterion (before and after the exchange). The findings of Bourqui (2006) and Wernli and Bourqui (2002) support the assumption that this power law fit can be extended to the range of $\tau$ between 12 and $48 \mathrm{~h}$. Thus our calculated STE flux, at least for the lower pressure surfaces and the PBL, is clearly in the diffusive regime described in Hall and Holzer (2003) for a large range of $\tau$ up to $96 \mathrm{~h}$.

While the amplitude of STE fluxes of mass and ozone are highly sensitive to this parameter, this is not true for the geographical patterns (now shown), such that our choice of $\tau=48 \mathrm{~h}$ (see Sect. 2), well above the lower limit of $8 \mathrm{~h}$ suggested by Bourqui (2006), does not limit the generality of the conclusions reached in this manuscript.

\section{Discussion}

In this section, we want to address caveats of the method, compare our results to previous studies and discuss our results in selected regions.

\subsection{Caveats of the method}

Caveats of our method are related, for instance, to the quality of the PBL height parameter and the ozone field in the ERAInterim data, as well as to the poor representation of subgrid-scale processes.

Our methodology to quantify deep STE relies strongly on the quality of the diagnosed PBL height in the ECMWF model. The method used in the ERA-Interim forecasts, following Troen and Mahrt (1986), is based on the bulk Richardson number and is suitable for global model output. Seidel et al. (2012) reported that the PBL height in ERAInterim is likely up to several $100 \mathrm{~m}$ too high, especially over high-elevation regions. We have investigated this influence by limiting the pressure at the PBL top to a minimum of $330 \mathrm{hPa}$, which roughly corresponds to the PBL height measured over the Tibetan Plateau in Yang et al. (2004). This limitation only affects the amplitudes of the deep STE fluxes in this region (a reduction of $\sim 25 \%$ in DJF and $\sim 35 \%$ in MAM), but the influence on the hemispherically integrated seasonal cycles is negligible (not shown). The importance of the Tibetan Plateau for deep STE is thus not fundamentally questioned by this investigation, but a considerable amount of deep STE in this region occurs when the PBL top reaches very high altitudes, and thus a possible bias of a few hundred metres can have a large impact on the exact values of the peak. Considering the recent measurements of very high boundary layers over the Tibetan Plateau (Chen et al., 2013), we chose not to restrict the PBL height in our study.

Although the ozone field in ERA-Interim agrees reasonably well with independent measurements, there are uncertainties on the order of $10 \%$ (Dragani, 2011) and spurious jumps occur in the time series (Fig. 19). Ozone values in the years between 1995 and 2004 suffer from changes in the assimilated satellite data, as described in Dragani (2011). In 1995, ozone data from only one satellite instrument (NOAA9 SBUV) were assimilated in ERA-Interim, and during 1996 and 1997, four new instruments were added. In the following $5 \mathrm{yr}$, the STT ozone flux increases strongly before dropping by nearly $50 \%$ in 2002 and 2003, which is likely due to three instruments going out of service and being replaced by three new satellite instruments. An in-depth investigation of the assimilation procedure in these years would be necessary to fully unravel this puzzling behaviour, which clearly prevents us from performing a trend analysis of the STT ozone flux. The seasonal cycles shown in Fig. 18 are not strongly affected by these years except for the increased interannual variability in certain months (see Sect. 6.3). 
A drawback of any Lagrangian method relying on trajectories calculated from resolved wind fields is the poor representation of sub-grid-scale convective fluxes. Gray (2003) estimated the contribution of sub-grid-scale transport of air across the tropopause to be $38 \%$ of the total transport, but the exact value changes significantly from case to case. Tang et al. (2011) found that deep convection reaching into the stratosphere mainly contributes to the STE ozone flux over the continents in $\mathrm{NH}$ spring and summer and enhances it by $19 \%$. Over the oceans, during the rest of the year and in the $\mathrm{SH}$, the contribution is much smaller. Therefore, we most likely underestimate the cross-tropopause fluxes, but using our method, we are not able to quantify this uncertainty. Our trajectory calculations also do not account for stretching and mixing of the air parcels along the transport pathways. Nevertheless, in many situations fluxes calculated by a trajectory approach show the same features and are of similar magnitude to those obtained from a Lagrangian particle diffusion model with parameterizations for convection and turbulence (Cristofanelli et al., 2003; Meloen et al., 2003).

\subsection{STE mass flux: comparison to Sprenger and Wernli (2003) and other studies}

Compared to the earlier reanalysis data set ERA-15 used by Sprenger and Wernli (2003) and James et al. (2003b), the increased spatial resolution of ERA-Interim (T255 in the horizontal and 60 levels up to $0.1 \mathrm{hPa}$ in the vertical vs. T106 and 31 vertical levels), the 4-D-Var data assimilation scheme and the strongly enhanced assimilation of satellite observations constitute major advances leading to an increased overall quality. Especially areas with sparse observations such as the tropopause region are represented more realistically (Dee et al., 2011). Also, the current climatology is compiled globally compared to the NH analysis of Sprenger and Wernli (2003) and covers a longer period ( $33 \mathrm{yr}$ vs. $15 \mathrm{yr}$ ). The methodology is refined in mainly two points: a 3-D labelling algorithm is used to distinguish between stratospheric air and isolated PV anomalies in the troposphere, and a new definition of deep exchange using the PBL height is introduced and replaces the $700 \mathrm{hPa}$ surface used in Sprenger and Wernli (2003).

Our results for the STT mass flux in the NH shown in Fig. 2 generally confirm the findings of Sprenger and Wernli (2003, their Figs. 2 and 4): the North Atlantic and North Pacific storm tracks are the regions with the largest STT mass flux. In the current study, the peak over the North Pacific is much more confined to the ocean than in Sprenger and Wernli (2003). This is probably due to a data assimilation problem in ERA-15, where radiosonde data clearly dominated the assimilation at the tropopause level and led to pronounced assimilation increments over the continents. In ERA-Interim, the assimilation increments are much smoother due to the large number of assimilated satellite data. Note that due to the different minimum residence time values, $48 \mathrm{~h}$ here and $96 \mathrm{~h}$ in Sprenger and Wernli
(2003), the quantitative values of all mass fluxes are larger by a factor of about two.

The TST mass flux very much resembles the one of Sprenger and Wernli (2003) in the regions north of $20^{\circ} \mathrm{N}$. In JJA, we report a strong peak over the eastern Mediterranean and Anatolia, which was present yet less pronounced in the earlier study.

The potential temperature distribution of all STT events in the NH is similar to the results in Sprenger and Wernli (2003, their Fig. 3), although the new distributions are broader due to exchanges in the tropics not included in the previous study. The first peak at roughly $320 \mathrm{~K}$ in JJA is clearly smaller than the one for the winter period (DJF) at $296 \mathrm{~K}$, which was not the case in Sprenger and Wernli (2003).

The mass flux of deep STT events into the PBL (top left in Fig. 5) and deep TST out of the PBL (top left in Fig. 6) in DJF can in principle be compared to the "destinations" (STT) and "origins" (TST) of Sprenger and Wernli (2003, their Fig. 5); however, the different criteria for deep events clearly have a large impact. For deep STT, the end of the North Pacific storm track and the start of the North Atlantic storm track are the preferred destinations in Sprenger and Wernli (2003). In our study, these areas also show high STT fluxes into the PBL, but the peak over the west coast of North America is shifted inland and the peak in the eastern US is shifted over the Atlantic. Furthermore, Sprenger and Wernli (2003), by definition of their criterion for deep STE, could not investigate trajectories that enter the PBL above highaltitude orography such as the Tibetan Plateau, which proves to be of high importance in this study. The situation for deep TST is similar because both studies emphasize the role of the starting regions of both $\mathrm{NH}$ storm tracks, but the peaks over the Tibetan Plateau and the mountain chains in western North America were not identified by Sprenger and Wernli (2003).

In order to compare our results for the total mass flux to previous studies, it is necessary to look at the tropopause in the extratropical $\mathrm{NH}$ only (here defined as the region north of $30^{\circ} \mathrm{N}$ ). Although our STT and TST fluxes across the extratropical tropopause $\left(110.2 \times 10^{16} \mathrm{~kg} \mathrm{yr}^{-1}\right.$ and $91.0 \times$ $10^{16} \mathrm{~kg} \mathrm{yr}^{-1}$, respectively) are about 40 times smaller than the values in James et al. (2003b), who did not use a similarly strict residence time threshold criterion, the net flux of $19.2 \times 10^{16} \mathrm{~kg} \mathrm{yr}^{-1}$ is of the same order of magnitude $\left(44.0 \times 10^{16} \mathrm{~kg} \mathrm{yr}^{-1}\right.$ in their study) and lies at the lower end of the range of values listed in Olsen et al. (2004, their Table 1).

\subsection{STT ozone flux: comparison to other studies}

In order to compare our results on STT ozone fluxes to other studies, we first assess the mean ozone mixing ratio at the tropopause shown in Figs. 14 and 18 (bottom row). In the hemispherical averages we find a nearly sinusoidal seasonal cycle with a maximum in summer and a minimum in winter and a fairly large interannual variability. This result thus 
agrees well with measurements from the MOZAIC campaign (Marenco et al., 1998) over the North Atlantic and Europe. Thouret et al. (2006) found a sinusoidal seasonal cycle of ozone at the 2 pvu tropopause with a maximum in May (120 ppbv) and a minimum in November (65 ppbv). If we restrict our analysis to the same region, we find a peak in June $(120 \mathrm{ppbv})$ and a minimum in December (70 ppbv). Our seasonal cycle is thus shifted in time by one month with respect to the MOZAIC measurements and agrees very well in amplitude. This comparison provides evidence that the ozone field in ERA-Interim is reasonable at the extratropical dynamical tropopause (cf. Fig. 15), which is of great importance for our calculations of the STT ozone flux.

Because the widely used methodology of Appenzeller et al. (1996) only allows for computation of the net (STTTST) ozone flux across the tropopause, it is not straightforward to compare the seasonal cycle of our STT ozone flux (Fig. 18) to other studies. Different choices of control surfaces representing the tropopause and latitudes separating the tropics from the extratropics further complicate the situation. In the studies using chemistry transport models (CTM) and refined versions of the methodology by Appenzeller et al. (1996), the tropopause is defined as 2 pvu (Hegglin and Shepherd, 2009), $3.5 \mathrm{pvu}$ (Olsen et al., 2004), ozone mixing ratio of $100 \mathrm{ppbv}$ (Hsu et al., 2005), or even $95 \mathrm{hPa}$ in the tropics and $256 \mathrm{hPa}$ in the extratropics (Gettelman et al., 2004). Nevertheless, all these studies roughly agree on the timing of the net ozone flux maximum (NH: between March and June; SH: in SON) and minimum (NH: SON; SH: JFM). The magnitude of the flux varies considerably for the $\mathrm{NH}$ minimum (between 3.9 and $20 \mathrm{Tg} \mathrm{month}^{-1}$ ) but agrees within a factor of two for the NH maximum (33-45 Tg month ${ }^{-1}$ ), as well as for both the SH maximum (27-50 Tg month $\left.{ }^{-1}\right)$ and minimum (13-20 Tg month ${ }^{-1}$ ).

For the sake of this comparison we therefore also calculated the TST ozone flux analogously to the STT ozone flux discussed in Sect. 4 such that the net ozone flux is given by the difference of these two quantities (see Fig. S10). We find maxima in June (NH, $1.64 \mathrm{Tg}$ month $^{-1}$ ) and July (SH, $1.58 \mathrm{Tgmonth}^{-1}$ ) and minima in September $(\mathrm{NH}$, $-2.27 \mathrm{Tg}$ month $^{-1}$ ) and February $\left(\mathrm{SH},-2.26 \mathrm{Tg}\right.$ month $^{-1}$ ). Our results disagree with the seasonal cycles found in the Eulerian studies both in amplitude and timing. The smaller values in our study are expected because method intercomparison studies have shown that Eulerian models are too diffusive and are likely to overestimate STE fluxes (Cristofanelli et al., 2003; Meloen et al., 2003), but it is not clear at first sight why we obtain net upward ozone fluxes in certain months. This points to a problem in the calculation of the TST ozone flux. Since tropospheric chemistry is neglected in ERA-Interim, the lifetime of ozone in the troposphere and thus also the ozone mixing ratios during TST events are very likely overestimated. The strong vertical gradients of ozone mixing ratios near the tropopause are not well represented, such that our TST ozone flux is unrealistically intense, lead- ing to a negative net flux in certain months. This is also true for the net ozone flux across the $3.5 \mathrm{pvu}$ control surface, where the maximum is higher by $30 \%$ when compared to the "control" data set (see bottom row in Fig. S4).

Assuming that the TST ozone flux is smaller than the STT ozone flux, one can in principle, as a very rough approximation, compare the seasonal cycle of the STT ozone flux in this study to the net flux in the Eulerian studies mentioned above. Indeed, our STT ozone flux matches their findings better than our net ozone flux. We find maxima of the STT ozone flux in June (NH, 23.3 Tg month ${ }^{-1}$ ) and January ( $\mathrm{SH}$, 18.9 $\mathrm{Tg}$ month $^{-1}$ ) and the minima are reached in December $\left(\mathrm{NH}, 14.0 \mathrm{Tg} \mathrm{month}^{-1}\right.$ ) and June (SH, 14.6 $\left.\mathrm{Tg} \mathrm{month}^{-1}\right)($ see Fig. 18).

While we find that the seasonal cycle of the STT ozone flux is governed by the ozone concentrations at the tropopause, the situation is very different for the subset of deep exchanges where the seasonality of the mass flux clearly dominates and the maximum deep STT ozone flux is reached in March in the $\mathrm{NH}$ and in September in the SH (Fig. 18). This is in very good agreement with Stohl et al. (2003) and other studies that found a late winter/early spring maximum of stratospheric influence on ozone concentrations at the surface in the NH (e.g. Lin et al., 2012; Lefohn et al., 2012). In order to roughly estimate the increase in ozone in the PBL due to deep STT, one can assume a certain PBL height, thus defining a "PBL volume", and calculate the change in ozone concentrations inside this volume due to the ozone flux into it. Using a PBL height of $1 \mathrm{~km}$, a flux of $1 \mathrm{~kg} \mathrm{~km}^{-2}$ month $^{-1}$ corresponds to an increase of the ozone concentration by 15.3 ppbv per day within the PBL. The daily ozone input from the stratosphere into the PBL estimated in this manner reaches several $100 \mathrm{ppbv}$ per day at the peaks of the deep STT ozone flux found in this study. These values are unrealistically high because mixing, wet and dry deposition, and chemical processes are changing the ozone concentrations in the free troposphere and the PBL. However, they highlight the substantial potential of stratospheric intrusions to influence surface ozone in certain regions and seasons.

The large interannual variability of the deep STT ozone flux in the months between December and April in the $\mathrm{NH}$ (Fig. 18c) originates from exceptionally large values in the winters of 1997, 2000, 2002, and 2008, and the large variability of the STT ozone flux in September in the SH (Fig. 18b, d) is explained by exceptionally large peaks in the years of 1996, 1999, 2000, and 2001. Generally, the years from 1998 to 2002 are characterized by a very strong seasonal cycle and an ozone flux that is around $15 \%$ larger than in the years before. To some extent, this can be confirmed by the MOZAIC measurements: Thouret et al. (2006) find 10-15\% higher ozone concentrations in the years 1998 and 1999. Their data, however, show a decrease to only $5 \%$ elevated levels in the years between 2001 and 2003, whereas our STT ozone flux stays roughly constant between 1999 and 2002 until it rapidly 
drops in 2002 and 2003. This further supports the assumption that there is a problem with the ozone field in ERA-Interim during this period.

\subsection{Regional aspects}

Western North America, stretching from the Rocky Mountains in the north to the western Sierra Madre in the south, is a region of high deep STT fluxes for both mass (Fig. 5) and ozone (Fig. 17). The maximum is reached in spring but fluxes are above average in all seasons. This result agrees well with recent studies that showed an important influence of STE in affecting ozone concentrations at the surface in this area (Langford et al., 2009; Lefohn et al., 2011, 2012; Lin et al., 2012). We also find that a lot of deep TST trajectories leave the PBL in this region, albeit slightly more to the east (Fig. 6). It seems that deep STT into the PBL occurs preferably on the upwind side of and right over the mountain ranges and the deep TST trajectories leave the PBL mostly on the downwind side.

This difference is also visible in the trends of the deep STT and deep TST mass fluxes (see Fig. S1). While deep STT mostly increases over western North America, the largest trend in deep TST is found over central North America, i.e. downwind of the mountain ranges. A further, interesting feature in this region is that while there is a negative trend in STT over the North Pacific, i.e. upstream of the region of interest, the trend in mass flux into the PBL is positive (see Fig. 13). This is also true for deep TST, albeit less clearly.

The STT mass flux over central Europe is comparatively intense in winter and spring and to a lesser degree also in autumn (see Fig. 2). This is also true for the STT ozone flux across the $600 \mathrm{hPa}$ surface (not shown) and supports the finding that the background ozone levels in the lower troposphere are affected by STT (Ordóñez et al., 2007). However, only in spring do the intrusions reach deep enough to influence the PBL (see Fig. 5). It is thus understandable that signatures of deep STT intrusions at the ground have mainly been observed at Alpine measurement sites in spring (Stohl et al., 2000; Trickl et al., 2010).

Both STT and TST mass fluxes in JJA have a distinct maximum over the eastern Mediterranean and Anatolia (see Figs. 2 and 3). This is likely due to deep tropopause folds associated with the subtropical jet stream, enhancing turbulent mixing and STE (Sprenger et al., 2003; Traub and Lelieveld, 2003; Tyrlis et al., 2014). In this region, there are elevated levels for deep STT in DJF and MAM (Fig. 5), indicating that deep stratospheric intrusions such as the one observed by Gerasopoulos et al. (2006) are not unusual.

Further to the east, the STT mass flux in JJA shows elevated values along the northern flank of the upper-level Asian monsoon anticyclone. Sprenger et al. (2003) found that this area is a hotspot for shallow and medium tropopause folds, which explains the enhanced STT flux. The connection between the Asian upper-level monsoon anticyclone and en- hanced tropopause folding activity in these regions has recently been investigated by Tyrlis et al. (2014).

\section{Conclusions}

We have compiled a global climatology of STE using the state-of-the-art reanalysis data set ERA-Interim over $33 \mathrm{yr}$ from 1979 to 2011. The well-established Lagrangian methodology has been refined with a 3-D labelling algorithm that distinguishes between the troposphere and the stratosphere (see Sect. 2.2) and a realistic representation of deep exchanges across the top of the PBL (see Sect. 2.3). In addition to the mass flux, assimilated ozone data have been used to calculate the ozone flux across the tropopause and into the PBL. The main results of this climatology are as follows:

- The geographical distribution of STE shows strong zonal asymmetry and pronounced seasonal cycles, especially for the subset of deep exchange events. The storm tracks over the North Atlantic, North Pacific, and the Southern Ocean, as well as mountain chains in the subtropics, are preferred regions of STE.

- There are clear hotspots of deep STT fluxes into the continental PBL. The Rocky Mountains and the other mountain ranges along the west coast of North America are affected all year around, with a clear peak in spring (MAM). There are also intense deep STT fluxes over the Tibetan Plateau during the whole year, with a peak in DJF. In the SH, the highest fluxes into the PBL are found over the Andes around $30^{\circ} \mathrm{S}$. In the storm tracks, especially over the North Atlantic and the North Pacific in DJF and the southern Indian Ocean in JJA, deep STT events transport stratospheric air into the marine PBL.

- Boundary layer air from the entrance of the North Atlantic and North Pacific storm tracks is rapidly transported into the stratosphere (deep TST) during all seasons but summer. Clear hotspots of deep TST can be found over the Rocky Mountains and mountain ranges nearby in spring (MAM) and over the Tibetan Plateau in DJF and MAM. The deep TST maxima are preferably located on the downwind side of the orography, to the east of the deep STT maxima, which are on the upwind side or directly over the high-altitude areas.

- STT dominates in the extratropics and TST in the tropics and polar regions. The mass flux by deep exchanges across the tropopause is limited to the extratropics and the flux into the PBL is shifted between roughly $15^{\circ}$ $(\mathrm{NH})$ and $30^{\circ}(\mathrm{SH})$ towards the Equator compared to where the associated air parcels cross the tropopause.

- The seasonal cycles of the mass fluxes vary strongly in amplitude and shape. STT is most intense during winter or early spring and reaches a minimum in summer 
in both hemispheres. For TST, the situation is more complex, as the deep TST mass flux is strongly out of phase with respect to the total TST mass flux. The seasonalities of the total STE fluxes are small. The seasonal cycles of deep STE are much more pronounced for both STT and TST in both hemispheres (seasonalities between $S=29 \%$ for deep TST and $S=83 \%$ for deep STT in the NH). The deep STT flux peaks in early spring in the $\mathrm{NH}$ and in winter in the $\mathrm{SH}$. In both hemispheres, the minimum is reached in summer.

- The analysis of potential temperatures at the exchange locations shows a broad and complex distribution in both hemispheres, further emphasizing that studies which focus on a few $\Theta$ surfaces miss a substantial part of the exchange events. There is a clear connection between $\Theta$ and latitude, such that the high- $\Theta$ events exclusively occur in the tropics. Deep STE occurs almost exclusively at $\Theta$ below $350 \mathrm{~K}$.

- The time series of globally integrated mass fluxes over the 33 yr from 1979 to 2011 show an increasing net downward flux and slightly decreasing gross fluxes. There are positive trends for both deep STT and deep TST mass fluxes but the downward flux increases twice as fast as the upward flux. Analysis of the geographical distribution of these trends reveals large regional differences. A notable feature is a poleward shift of the TST mass flux in the subtropics over the Pacific and the Indian oceans. There are indications for an accompanying equatorward shift of the STT mass flux in the same regions but the signal is less clear.

- The ozone flux across the tropopause is significantly influenced by the seasonal cycle and geographical distribution of ozone concentrations at the tropopause. There are pronounced peaks over the Andes (DJF), the Himalayas (MAM), and the Tibetan Plateau (MAM, JJA), as well as central North America, Anatolia, the Equator over the Indian Ocean, and much of eastern Asia in JJA.

- The ozone flux due to deep STT into the PBL is dominated by the seasonal and geographical variations of the deep STT mass flux. The global hotspots, where surface ozone concentrations are most likely influenced by STE, are the mountain ranges along the west coast of North America, especially in MAM, and the Tibetan Plateau in all seasons except for SON. In the latter region, the very high orography combined with a high mixing layer enables quasi-horizontal transport into the PBL, whereas for the former region, considerable vertical transport is necessary.

- The seasonal cycle of the STT ozone flux peaks in summer, which contrasts with the mass flux that is nearly at its minimum at that time. This shows that the STT ozone flux is dominated by the variation in prevailing ozone concentrations at the tropopause. The seasonal cycle of the deep STT ozone flux, on the other hand, is clearly dominated by changes in the deep STT mass flux and peaks in early spring.

- The ozone field assimilated in ERA-Interim produces a reasonable seasonal cycle of ozone at the tropopause, yet there might be significant problems with the assimilation of data from satellite instruments during the period from 1995 to 2004. Our time series, which is especially affected by these problems, should thus be interpreted with care. Nevertheless, we obtain meaningful results for the geographical and seasonal distribution of the downward ozone flux across the tropopause and into the PBL.

- The mass and ozone fluxes across the tropopause, pressure surfaces and into as well as out of the PBL depend on the minimum residence time $\tau$. This dependence follows a power law (proportional to $\tau^{\kappa}, \kappa \sim-0.5$ ) with remarkable accuracy $\left(R^{2}>0.995\right)$.

- The reduction in STT mass flux across the 3.5 pvu surface, compared to the 2 pvu surface, is partly compensated for by the increase in ozone concentrations, leading to a reduction of only approximately $10 \%$ of the STT ozone flux, as well as a similar seasonal cycle. The deep STT ozone flux, on the other hand, is significantly reduced by more than $60 \%$ when considering the 3.5 pvu control surface.

- Since the spatial and temporal resolution of our data is too coarse to represent deep convection well, we are certainly underestimating the effect of this process. For this reason, high-resolution STE diagnostics such as those presented by Bourqui et al. (2012) and studies using mesoscale numerical weather prediction models (Gray, 2003; Lin et al., 2012) are of great importance.

\section{Supplementary material related to this article is available online at http://www.atmos-chem-phys.net/14/ 913/2014/acp-14-913-2014-supplement.pdf.}

Acknowledgements. We thank the ECMWF and MeteoSwiss for providing access to the meteorological data, and H. Sodemann, S. Pfahl, and A. Kunz for useful discussions.

Edited by: P. Haynes

\section{References}

Appenzeller, C., Holton, J. R., and Rosenlof, K. H.: Seasonal variation of mass transport across the tropopause, J. Geophys. Res., 101, 15071-15078, doi:10.1029/96JD00821, 1996. 
Berthet, G., Esler, J. G., and Haynes, P. H.: A Lagrangian perspective of the tropopause and the ventilation of the lowermost stratosphere, J. Geophys. Res., 112, D18102, doi:10.1029/2006JD008295, 2007.

Bithell, M., Gray, L. J., and Cox, B. D.: A three-dimensional view of the evolution of midlatitude stratospheric intrusions, J. Atmos. Sci., 56, 673-688, 1999.

Bourqui, M.: Analysis and quantification of STE: A novel approach, Ph.D. thesis, ETH Zurich, Switzerland, 2001.

Bourqui, M. S.: Stratosphere-troposphere exchange from the Lagrangian perspective: a case study and method sensitivities, Atmos. Chem. Phys., 6, 2651-2670, doi:10.5194/acp-6-2651-2006, 2006.

Bourqui, M. and Trepanier, P.: Descent of deep stratospheric intrusions during the IONS August 2006 campaign, J. Geophys. Res., 115, D18301, doi:10.1029/2009JD013183, 2010.

Bourqui, M. S., Yamamoto, A., Tarasick, D., Moran, M. D., Beaudoin, L.-P., Beres, I., Davies, J., Elford, A., Hocking, W., Osman, M., and Wilkinson, R.: A new global real-time Lagrangian diagnostic system for stratosphere-troposphere exchange: evaluation during a balloon sonde campaign in eastern Canada, Atmos. Chem. Phys., 12, 2661-2679, doi:10.5194/acp-12-26612012, 2012.

Chen, B., Xu, X. D., Yang, S., and Zhao, T. L.: Climatological perspectives of air transport from atmospheric boundary layer to tropopause layer over Asian monsoon regions during boreal summer inferred from Lagrangian approach, Atmos. Chem. Phys., 12, 5827-5839, doi:10.5194/acp-12-5827-2012, 2012.

Chen, X., Anel, J. A., Su, Z., de la Torre, L., Kelder, H., van Peet, J., and Ma, Y.: The deep atmospheric boundary layer and its significance to the stratosphere and troposphere exchange over the Tibetan Plateau, PLOS ONE, 8, e56909, doi:10.1371/journal.pone.0056909, 2013.

Collins, W. J., Derwent, R. G., Garnier, B., Johnson, C. E., Sanderson, M. G., and Stevenson, D. S.: Effect of stratospheretroposphere exchange on the future tropospheric ozone trend, J. Geophys. Res., 108, 8528, doi:10.1029/2002JD002617, 2003.

Cooper, O. R., Stohl, A., Hübler, G., Hsie, E. Y., Parrish, D. D., Tuck, A. F., Kiladis, G. N., Oltmans, S. J., Johnson, B. J., Shapiro, M., Moody, J. L., and Lefohn, A. S.: Direct transport of midlatitude stratospheric ozone into the lower troposphere and marine boundary layer of the tropical Pacific Ocean, J. Geophys. Res., 110, D23310, doi:10.1029/2005JD005783, 2005.

Cristofanelli, P., Bonasoni, P., Collins, W., Feichter, J., Forster, C., James, P., Kentarchos, A. S., Kubik, P. W., Land, C., Meloen, J., Roelofs, G. J., Siegmund, P., Sprenger, M., Schnabel, C., Stohl, A., Tobler, L., Tositti, L., Trickl, T., and Zanis, P.: Stratosphereto-troposphere transport: A model and method evaluation, J. Geophys. Res., 108, 8525, doi:10.1029/2002JD002600, 2003.

Cristofanelli, P., Bracci, A., Sprenger, M., Marinoni, A., Bonafè, U., Calzolari, F., Duchi, R., Laj, P., Pichon, J. M., Roccato, F., Venzac, H., Vuillermoz, E., and Bonasoni, P.: Tropospheric ozone variations at the Nepal Climate ObservatoryPyramid (Himalayas, $5079 \mathrm{~m}$ a.s.1.) and influence of deep stratospheric intrusion events, Atmos. Chem. Phys., 10, 6537-6549, doi:10.5194/acp-10-6537-2010, 2010.

Danielsen, E.: Stratospheric-tropospheric exchange based on radioactivity, ozone and potential vorticity, J. Atmos. Sci., 25, 502$518,1968$.
Davies, T. D. and Schuepbach, E.: Episodes of high ozone concentrations at the earth's surface resulting from transport down from the upper troposphere/lower stratosphere: a review and case studies, Atmos. Environ., 28, 53-68, doi:10.1016/13522310(94)90022-1, 1994.

Dee, D. P., Uppala, S. M., Simmons, A. J., Berrisford, P., Poli, P., Kobayashi, S., Andrae, U., Balmaseda, M. A., Balsamo, G., Bauer, P., Bechtold, P., Beljaars, A. C. M., van de Berg, L., Bidlot, J., Bormann, N., Delsol, C., Dragani, R., Fuentes, M., Geer, A. J., Haimberger, L., Healy, S. B., Hersbach, H., Holm, E. V., Isaksen, L., Kallberg, P., Köhler, M., Matricardi, M., McNally, A. P., Monge-Sanz, B. M., Morcette, J.-J., Park, B.-K., Peubey, C., de Rosnay, P., Tavolato, C., Thepaut, J.-N., and Vitart, F.: The ERA-Interim reanalysis: Configuration and performance of the data assimilation system, Q. J. Roy. Meteor. Soc., 137, 553-597, doi:10.1002/qj.828, 2011.

Dragani, R.: On the quality of the ERA-Interim ozone reanalyses: comparisons with satellite data, Q. J. Roy. Meteor. Soc., 137, 1312-1326, doi:10.1002/qj.821, 2011.

Ertel, H.: Ein neuer hydrodynamischer Wirbelsatz, Meteorol. Z., 59, 271-281, 1942.

Forster, P. V., Ramaswamy, P., Artaxo, T., Berntsen, R., Betts, D. W., Fahey, J., Haywood, J., Lean, D. C., Lowe, G., Myhre, J., Nganga, R., Prinn, G., Raga, M., Schulz, R., and Van Dorland, R.: Changes in atmospheric constituents and in radiative forcing, Vol. 20, Cambridge University Press, Cambridge, UK, 2007.

Fueglistaler, S., Wernli, H., and Peter, T.: Tropical troposphereto-stratosphere transport inferred from trajectory calculations, J. Geophys. Res., 109, D03108, doi:10.1029/2003JD004069, 2004.

Gauss, M., Myhre, G., Pitari, G., Prather, M. J., Isaksen, I. S. A., Berntsen, T. K., Brasseur, G. P., Dentener, F. J., Derwent, R. G., Hauglustaine, D. A., Horowitz, L. W., Jacob, D. J., Johnson, M., Law, S., Mickley, L. J., Müller, J.-F., Plantevin, P.-H., Pyle, J. A., Rogers, H. L., Stevenson, D. S., Sundet, J. K., van Weele, M., and Wild, O.: Radiative forcing in the 21st century due to ozone changes in the troposphere and the lower stratosphere, J. Geophys. Res., 108, 4292, doi:10.1029/2002JD002624, 2003.

Gerasopoulos, E., Zanis, P., Papastefanou, C., Zerefos, C., Ioannidou, A., and Wernli, H.: A complex case study of down to the surface intrusions of persistent stratospheric air over the Eastern Mediterranean, Atmos. Environ., 40, 4113-4125, doi:10.1016/j.atmosenv.2006.03.022, 2006.

Gettelman, A. and Sobel, A.: Direct diagnoses of stratospheretroposphere exchange, J. Atmos. Sci., 57, 3-16, 2000.

Gettelman, A., Kinnison, D., Dunkerton, T., and Brasseur, G.: Impact of monsoon circulations on the upper troposphere and lower stratosphere, J. Geophys. Res., 109, D22101, doi:10.1029/2004JD004878, 2004.

Gray, S.: A case study of stratosphere to troposphere transport: The role of convective transport and the sensitivity to model resolution, J. Geophys. Res., 108, 4590, doi:10.1029/2002JD003317, 2003.

Hall, T. and Holzer, M.: Advective-diffusive mass flux and implications for stratosphere-troposphere exchange, Geophys. Res. Lett., 30, 1222, doi:10.1029/2002GL016419, 2003.

Hegglin, M. and Shepherd, T.: Large climate-induced changes in ultraviolet index and stratosphere-to-troposphere ozone flux, Nat. Geosci., 2, 687-691, doi:10.1038/NGEO604, 2009. 
Hoinka, K. P.: The tropopause: discovery, definition and demarcation, Meteorol. Z., 6, 281-303, 1997.

Hoinka, K. P.: Statistics of the global tropopause pressure, Mon. Weather Rev., 126, 3303-3325, 1998.

Holton, J. R., Haynes, P. H., McIntyre, M. E., Douglass, A. R., Rood, R. B., and Pfister, L.: Stratosphere-troposphere exchange, Rev. Geophys., 33, 403-440, 1995.

Hoskins, B. J., McIntyre, M. E., and Robertson, A. W.: On the use and significance of isentropic potential vorticity maps, Q. J. Roy. Meteor. Soc., 111, 877-946, 1985.

Hsu, J., Prather, M. J., and Wild, O.: Diagnosing the stratosphereto-troposphere flux of ozone in a chemistry transport model, J. Geophys. Res., 110, D19305, doi:10.1029/2005JD006045, 2005.

James, P., Stohl, A., Forster, C., Eckhardt, S., Seibert, P., and Frank, A.: A 15-year climatology of stratosphere-troposphere exchange with a Lagrangian particle dispersion model: 1 . Methodology and validation, J. Geophys. Res., 108, 8519, doi:10.1029/2002JD002637, 2003a.

James, P., Stohl, A., Forster, C., Eckhardt, S., Seibert, P., and Frank, A.: A 15-year climatology of stratosphere-troposphere exchange with a Lagrangian particle dispersion model: 2. Mean climate and seasonal variability, J. Geophys. Res., 108, 8522, doi:10.1029/2002JD002639, 2003b.

Juckes, M.: The mass flux across the tropopause: Quasi-geostrophic theory, Q. J. Roy. Meteor. Soc., 123, 71-99, 1997.

Junge, C. E.: Global ozone budget and exchange between stratosphere and troposphere, Tellus, 4, 363-377, 1962.

Kentarchos, A. S. and Roelofs, G. J.: A model study of stratospheric ozone in the troposphere and its contribution to tropospheric $\mathrm{OH}$ formation, J. Geophys. Res., 108, 8517, doi:10.1029/2002JD002598, 2003.

Knowlton, K., Rosenthal, J. E., Hogrefe, C., Lynn, B., Gaffin, S., Goldberg, R., Rosenzweig, C., Civerolo, K., Ku, J. Y., and Kinney, P. L.: Assessing ozone-related health impacts under a changing climate, Environ. Health Persp., 112, 1557, doi:10.1289/ehp.7163, 2004.

Kuang, S., Newchurch, M. J., Burris, J., Wang, L., Knupp, K., and Huang, G.: Stratosphere-to-troposphere transport revealed by ground-based lidar and ozonesonde at a midlatitude site, J. Geophys. Res., 117, 18305, doi:10.1029/2012JD017695, 2012.

Kunz, A., Konopka, P., Müller, R., and Pan, L. L.: Dynamical tropopause based on isentropic potential vorticity gradients, J. Geophys. Res., 116, 2156-2202, doi:10.1029/2010JD014343, 2011.

Lamarque, J.-F. and Hess, P. G.: Cross-tropopause mass exchange and potential vorticity budget in a simulated tropopause folding, J. Atmos. Sci., 51, 2246-2246, 1994.

Langford, A. O., Aikin, K. C., Eubank, C. S., and Williams, J. E.: Stratospheric contribution to high surface ozone in Colorado during springtime, Geophys. Res. Lett., 36, L12801, doi:10.1029/2009GL038367, 2009.

Lefohn, A. S., Wernli, H., Shadwick, D., Limbach, S., Oltmans, S. J., and Shapiro, M.: The importance of stratospherictropospheric transport in affecting surface ozone concentrations in the western and northern tier of the United States, Atmos. Environ., 45, 4845-4857, doi:10.1016/j.atmosenv.2011.06.014, 2011.

Lefohn, A. S., Wernli, H., Shadwick, D., Oltmans, S. J., and Shapiro, M.: Quantifying the importance of stratospheric- tropospheric transport on surface ozone concentrations at highand low-elevation monitoring sites in the United States, Atmos. Environ., 62, 646-656, doi:10.1016/j.atmosenv.2012.09.004, 2012.

Lin, M., Fiore, A. M., Cooper, O. R., Horowitz, L. W., Langford, A. O., Levy, H., Johnson, B. J., Naik, V., Oltmans, S. J., and Senff, C. J.: Springtime high surface ozone events over the western United States: Quantifying the role of stratospheric intrusions, J. Geophys. Res., 117, D00V22, doi:10.1029/2012JD018151, 2012.

Lippmann, M.: Health effects of ozone a critical review, JAPCA, 39, 672-695, doi:10.1080/08940630.1989.10466554, 1989.

Marenco, A., Thouret, V., Nédélec, P., Smit, H., Helten, M., Kley, D., Karcher, F., Simon, P., Law, K., Pyle, J. A., Poschmann, G., von Wrede, R., Hume, C., and Cook, T.: Measurement of ozone and water vapor by Airbus in-service aircraft: The MOZAIC airborne program, An overview, J. Geophys. Res., 103, 2563125642, 1998.

Meloen, J., Siegmund, P., van Velthoven, P., Kelder, H., Sprenger, M., Wernli, H., Kentarchos, A. S., Roelofs, G. J., Feichter, J., Land, C., Forster, C., James, P., Stohl, A., Collins, W., and Cristofanelli, P.: Stratosphere-troposphere exchange: A model and method intercomparison, J. Geophys. Res., 108, 8526 , doi:10.1029/2002JD002274, 2003.

Olsen, M. A., Schoeberl, M. R., and Douglass, A. R.: Stratospheretroposphere exchange of mass and ozone, J. Geophys. Res., 109, D24114, doi:10.1029/2004JD005186, 2004.

Orbe, C., Holzer, M., and Polvani, L. M.: Flux distributions as robust diagnostics of stratosphere-troposphere exchange, J. Geophys. Res., 117, D01302, doi:10.1029/2011JD016455, 2012.

Ordóñez, C., Brunner, D., Staehelin, J., Hadjinicolaou, P., Pyle, J. A., Jonas, M., Wernli, H., and Prévôt, A. S. H.: Strong influence of lowermost stratospheric ozone on lower tropospheric background ozone changes over Europe, Geophys. Res. Lett., 34, L07805, doi:10.1029/2006GL029113, 2007.

Roelofs, G. J. and Lelieveld, J.: Model study of the influence of cross-tropopause $\mathrm{O}_{3}$ transports on tropospheric $\mathrm{O}_{3}$ levels, Tellus B, 49, 38-55, 1997.

Schmidt, T., Wickert, J., Beyerle, G., and Heise, S.: Global tropopause height trends estimated from GPS radio occulation data, Geophys. Res. Lett., 35, L11806, doi:10.1029/2008GL034012, 2008.

Schoeberl, M.: Extratropical stratosphere-troposphere mass exchange, J. Geophys. Res., 109, D13303, doi:10.1029/2004JD004525, 2004.

Seidel, D. and Randel, W.: Variability and trends in the global tropopause estimated from radiosonde data, J. Geophys. Res., 111, D21101, doi:10.1029/2006JD007363, 2006.

Seidel, D. J., Zhang, Y., Beljaars, A., Golaz, J.-C., Jacobson, A. R., and Medeiros, B.: Climatology of the planetary boundary layer over the continental United Stats and Europe, J. Geophys. Res., 117, D17106, doi:10.1029/2012JD018143, 2012.

Seo, K. and Bowman, K.: A climatology of isentropic crosstropopause exchange, J. Geophys. Res., 106, 28159-28172, 2001.

Simmons, A., Uppala, S., Dee, D., and Kobayashi, S.: ERA-Interim: New ECMWF reanalysis products from 1989 onwards, ECMWF newsletter, 110, 26-35, 2006. 
Solomon, S., Qin, D., Manning, M., Alley, R. B., Berntsen, T., Bindoff, N. L., Chen, Z., Chidthaisong, A., Gregory, J. M., Hegerl, G. C., Heimann, M., Hewitson, B., Hoskins, B. J., Joos, F., Jouzel, J., Kattsov, V., Lohmann, U., Matsuno, T., Molina, M., Nicholls, N., Overpeck, J., Raga, G., Ramaswamy, V., Ren, J., Rusticucci, M., Somerville, R., Stocker, T. F., Stouffer, R. J., Whetton, P., Wood, R. A., and Wratt, D.: Climate change 2007: the physical science basis: contribution of Working Group I to the Fourth Assessment Report of the Intergovernmental Panel on Climate Change, Cambridge University Press, Cambridge, UK, 2007.

Sprenger, M. and Wernli, H.: A northern hemispheric climatology of cross-tropopause exchange for the ERA15 time period (19791993), J. Geophys. Res., 108, 8521, doi:10.1029/2002JD002636, 2003.

Sprenger, M., Croci Maspoli, M., and Wernli, H.: Tropopause folds and cross-tropopause exchange: A global investigation based upon ECMWF analyses for the time period March 2000 to February 2001, J. Geophys. Res., 108, 8518, doi:10.1029/2002JD002587, 2003.

Steinbrecht, W., Claude, H., Köhler, U., and Hoinka, K.: Correlations between tropopause height and total ozone: Implications for long-term changes, J. Geophys. Res., 103, 19183-19192, doi:10.1029/98JD01929, 1998.

Stevenson, D. S., Dentener, F. J., Schultz, M. G., Ellingsen, K., van Noije, T. P. C., Wild, O., Zeng, G., Amann, M., Atherton, C. S., Bell, N., Bergmann, D. J., Bey, I., Butler, T., Cofala, J., Collins, W. J., Derwent, R. G., Doherty, R. M., Drevet, J., Eskes, H. J., Fiore, A. M., Gauss, M., Hauglustaine, D. A., Horowitz, L. W., Isaksen, I. S. A., Krol, M. C., Lamarque, J.-F., Lawrence, M. G., Montanaro, V., Müller, J.-F., Pitari, G., Prather, M. J., Pyle, J. A., Rast, S., Rodriguez, J. M., Sanderson, M. G., Savage, N. H., Shindell, D. T., Strahan, S. E., Sudo, K., and Szopa, S.: Multimodel ensemble simulations of present-day and near-future tropospheric ozone, J. Geophys. Res., 111, D08301, doi:10.1029/2005JD006338, 2006.

Stohl, A., Spichtinger-Rakowsky, N., Bonasoni, P., Feldmann, H., Memmesheimer, M., Scheel, H., Trickl, T., Hübener, S., Ringer, W., and Mandl, M.: The influence of stratospheric intrusions on alpine ozone concentrations, Atmos. Environ., 34, 1323-1354, doi:10.1016/S1352-2310(99)00320-9, 2000.

Stohl, A., Bonasoni, P., Cristofanelli, P., Collins, W., Feichter, J., Frank, A., Forster, C., Gerasopoulos, E., Gäggeler, H., James, P., Kentarchos, A. S., Kromp-Kolb, H., Krüger, B., Land, C., Meloen, J., Papayannis, A., Priller, A., Seibert, P., Sprenger, M., Roelofs, G. J., Scheel, H. E., Schnabel, C., Siegmund, P., Tobler, L., Trickl, T., Wernli, H., Wirth, V., Zanis, P., and Zerefos, C.: Stratosphere-troposphere exchange: A review, and what we have learned from STACCATO, J. Geophys. Res., 108, 8516, doi:10.1029/2002JD002490, 2003.

Stohl, A., Forster, C., Frank, A., Seibert, P., and Wotawa, G.: Technical note: The Lagrangian particle dispersion model FLEXPART version 6.2, Atmos. Chem. Phys., 5, 2461-2474, doi:10.5194/acp-5-2461-2005, 2005.

Tang, Q., Prather, M. J., and Hsu, J.: Stratosphere-troposphere exchange ozone flux related to deep convection, Geophys. Res. Lett., 38, L03806, doi:10.1029/2010GL046039, 2011.
Thouret, V., Cammas, J.-P., Sauvage, B., Athier, G., Zbinden, R., Nédélec, P., Simon, P., and Karcher, F.: Tropopause referenced ozone climatology and inter-annual variability (1994-2003) from the MOZAIC programme, Atmos. Chem. Phys., 6, 1033-1051, doi:10.5194/acp-6-1033-2006, 2006.

Traub, M. and Lelieveld, J.: Cross-tropopause transport over the eastern Mediterranean, J. Geophys. Res., 108, 4712, doi:10.1029/2003JD003754, 2003.

Trickl, T., Feldmann, H., Kanter, H.-J., Scheel, H.-E., Sprenger, M., Stohl, A., and Wernli, H.: Forecasted deep stratospheric intrusions over Central Europe: case studies and climatologies, Atmos. Chem. Phys., 10, 499-524, doi:10.5194/acp-10-499-2010, 2010.

Troen, I. and Mahrt, L.: A simple model of the atmospheric boundary layer; sensitivity to surface evaporation, Bound.-Lay. Meteorol., 37, 129-148, 1986.

Tyrlis, E., Škerlak, B., Sprenger, M., Wernli, H., Zittis, G., and Lelieveld, J.: On the linkage between the Asian summer monsoon and tropopause folds over the eastern Mediterranean and the Middle East, J. Geophys. Res., accepted, 2014.

Vingarzan, R.: A review of surface ozone background levels and trends, Atmos. Environ., 38, 3431-3442, doi:10.1016/j.atmosenv.2004.03.030, 2004.

Von Engeln, A. and Teixeira, J.: A planetary boundary layer height climatology derived from ECMWF Re-analysis data, J. Climate, doi:10.1175/JCLI-D-12-00385.1, 2013.

Wei, M.: A new formulation of the exchange of mass and trace constituents between the stratosphere and troposphere, J. Atmos. Sci., 44, 3079-3086, 1987.

Wernli, H. and Bourqui, M.: A Lagrangian 1-year climatology of (deep) cross-tropopause exchange in the extratropical Northern Hemisphere, J. Geophys. Res., 107, 4021, doi:10.1029/2001JD000812, 2002.

Wernli, H. and Davies, H. C.: A Lagrangian-based analysis of extratropical cyclones. I: The method and some applications, Q. J. Roy. Meteor. Soc., 123, 467-489, 1997.

Wild, O.: Modelling the global tropospheric ozone budget: exploring the variability in current models, Atmos. Chem. Phys., 7, 2643-2660, doi:10.5194/acp-7-2643-2007, 2007.

Wirth, V. and Egger, J.: Diagnosing extratropical synoptic-scale stratosphere-troposphere exchange: A case study, Q. J. Roy. Meteor. Soc., 125, 635-655, doi:10.1002/qj.49712555413, 1999.

WMO: Meteorology - A three-dimensional science, WMO Bull., IV, 134-138, 1957

Yanai, M. and Li, C.: Mechanism of heating and the boundary layer over the Tibetan Plateau, Mon. Weather Rev., 122, 305-323, 1994.

Yang, K., Koike, T., Fujii, H., Tamura, T., Xu, X., Bian, L., and Zhou, M.: The daytime evolution of the atmospheric boundary layer and convection over the Tibetan Plateau: observations and simulations, J. Meteor. Soc. Japan, 82, 1777-1792, doi:10.2151/jmsj.82.1777, 2004.

Zeng, G. and Pyle, J. A.: Changes in tropospheric ozone between 2000 and 2100 modeled in a chemistry-climate model, Geophys. Res. Lett., 30, 1392, doi:10.1029/2002GL016708, 2003. 